\title{
Supercube grains leading to a strong cube texture and a broad grain size distribution after recrystallization
}

Lin, F.X.; Zhang, Y. B.; Pantleon, W.; Juul Jensen, D.

Published in:

Philosophical Magazine

Link to article, DOI:

$10.1080 / 14786435.2015 .1063787$

Publication date:

2015

Document Version

Peer reviewed version

Link back to DTU Orbit

Citation (APA):

Lin, F. X., Zhang, Y. B., Pantleon, W., \& Juul Jensen, D. (2015). Supercube grains leading to a strong cube texture and a broad grain size distribution after recrystallization. Philosophical Magazine, 95(22), 2427-2449. https://doi.org/10.1080/14786435.2015.1063787

\section{General rights}

Copyright and moral rights for the publications made accessible in the public portal are retained by the authors and/or other copyright owners and it is a condition of accessing publications that users recognise and abide by the legal requirements associated with these rights.

- Users may download and print one copy of any publication from the public portal for the purpose of private study or research.

- You may not further distribute the material or use it for any profit-making activity or commercial gain

- You may freely distribute the URL identifying the publication in the public portal 


\title{
Supercube grains leading to a strong cube texture and a broad grain size distribution after recrystallization
}

\author{
F.X. Lin ${ }^{\mathrm{a}^{*}}$, Y.B. Zhang ${ }^{\mathrm{a}}$, W. Pantleon ${ }^{\mathrm{b}}$, D. Juul Jensen ${ }^{\mathrm{a}}$ \\ ${ }^{\mathrm{a}}$ Danish-Chinese Center for Nanometals, Section for Materials Science and Advanced \\ Characterization, Department of Wind Energy, Technical University of Denmark, Risø campus, \\ 4000 Roskilde, Denmark \\ ${ }^{\mathrm{b}}$ Section for Materials and Surface Engineering, Department of Mechanical Engineering, \\ Technical University of Denmark, 2800 Kongens Lyngby, Denmark \\ *Corresponding author. Tel: +45 4677 5872; Fax: +45 4677 5758; Email address: lnfe@dtu.dk; \\ Postal address: Frederiksborgvej 399, Building 228, Roskilde, 4000 Denmark.
}

\begin{abstract}
This work revisits the classical subject of recrystallization of cold-rolled copper. Two characterization techniques are combined: 3-dimensional X-ray diffraction using synchrotron Xrays, which is used to measure the growth kinetics of individual grains in situ, and electron backscatter diffraction, which is used for statistical analysis of the microstructural evolution. As the most striking result, the strong cube texture after recrystallization is found to be related to a few super large cube grains, which were named supercube grains. These few supercube grains become large due to higher growth rates. However, most other cube grains do not grow preferentially. Because of the few supercube grains, the grain size distribution after recrystallization is broad. Reasons for the higher growth rates of supercube grains are discussed, and are related to the local deformed microstructure.
\end{abstract}

Keywords: copper, recrystallization, kinetics, texture, 3-dimensional X-ray diffraction (3DXRD), electron backscatter diffraction (EBSD)

\section{Introduction}

Recrystallization is a thermally activated process, whereby new defect-free grains emerge and grow at the expense of the deformed matrix. When new recrystallized grains replace the deformed matrix, the texture of the sample often changes. A strong cube texture $(\{100\}<001>)$ typically forms after recrystallization of face centered cubic metals with medium to high stacking 
fault energy (e.g. $\mathrm{Cu}, \mathrm{Al}, \mathrm{Ni}$ ) cold-rolled to high strains. In literature, the explanation for the strong cube texture is often related to oriented nucleation (e.g. [1]) and/or oriented growth (e.g. [2]). Copper is one the most discussed materials, probably because the recrystallization texture in cold-rolled copper seems to be sensitive to the chemical compositions and many processing parameters [3-11].

Recrystallization kinetics during isothermal annealing is usually described as the increase of recrystallized volume fraction $\left(V_{V}\right)$ as a function of annealing time $(t)$. But evolutions of other microstructural parameters, such as average grain size, number of recrystallizing grains per unit volume, or average growth rate of recrystallizing grains, are also necessary to understand the kinetics. Most investigations of recrystallization kinetics are based on statistical analysis of a series of partially recrystallized samples characterized by optical or electron microscopy [12-15]. With electron backscatter diffraction (EBSD), the microstructure and local texture can be mapped simultaneously. Consequently, the kinetics of recrystallizing grains belonging to a specific texture component (e.g. the cube texture) can be determined. For example, Juul Jensen found that the average growth rate of cube oriented grains was 2-3 times that of noncube grains during recrystallization of cold-rolled aluminium and copper [16], which supports oriented growth. Samajdar and Doherty found that the frequency of cube grains in warm-rolled aluminium was more than 10 times that expected for random nucleation [17], which supports oriented nucleation.

One limitation of the statistical method is that it provides only average information. The recrystallizing grains, at least those belonging to the same texture component, are treated as an ensemble. More recently, 3D X-ray diffraction (3DXRD) microscopy has been developed and used to study recrystallization kinetics [18]. With this technique, the growth kinetics of individual grains inside a bulk sample can be measured during in situ annealing. The results for aluminum samples rolled to various strains have shown that each grain follows its own kinetics [19-21]. The growth rates of different grains, as well as the activation energies, vary largely. Godiksen et al. simulated effects of growth rate distributions on recrystallization, and found that growth rate distributions significantly affected the microstructure, texture, and kinetics [22]. Until now, only a few growth curves of individual grains have been measured in copper [23,24], and these growth curves appear to be different from those observed in aluminum. 
This work investigates the recrystallization kinetics of cold-rolled copper using both statistical and in situ methods. The statistical method using EBSD was applied to compare the kinetics of cube and noncube grains and to characterize the microstructures after annealing to various recrystallized fractions, whereby we identified a group of cube grains, named supercube grains, as the key for the cube texture development. 3DXRD was used to obtain growth curves of individual grains in situ, focusing on the difference between supercube and other cube grains. It has to be noted that the present 3DXRD experiment is not optimized to study nucleation mechanisms, and no results shall be given on nucleation mechanisms for the two types of cube grains. The experiment is on the contrary optimized to characterize the nucleation and growth kinetics of the supercube and other cube grains, and thus enables to analyze the evolution of the texture and the grain size distribution, which is the purpose of the present paper. It is clear that recrystallization depends on the deformation microstructure, in which recrystallization occurs [25]. Therefore, the present 3DXRD measurements are supplemented by an ex situ EBSD experiment with the aim of relating the growth kinetics of a supercube grain to the local deformation microstructure. This is discussed as the final part of this paper.

\section{Experimental}

2.1 Material and rolling process

The material was oxygen free high conductivity copper (99.95\% purity), and the chemical composition is listed in Table 1. In order to obtain a starting material with a relatively small grain size, the as-received material was annealed at $650{ }^{\circ} \mathrm{C}$ for $2 \mathrm{~h}$, cold-rolled to a von Mises strain $\varepsilon_{\mathrm{vM}}=0.8(50 \%$ reduction in thickness $)$, and annealed at $450{ }^{\circ} \mathrm{C}$ for $1 \mathrm{~h}$. Figure 1 a shows the microstructure of the starting material. The grain size, determined by the line intercept method, is $10 \mu \mathrm{m}$ if twin boundaries are considered, and is $22 \mu \mathrm{m}$ if twin boundaries are ignored. The texture of the starting material is weak (see Figure 1b). The volume fraction of the cube texture component (maximum $15^{\circ}$ deviation from the ideal cube orientation $\{100\}<001>$ ) is $2 \%$, which is close to that in samples with a random texture.

The starting material was cold-rolled to $\varepsilon_{\mathrm{VM}}=2.7$ ( $90 \%$ reduction in thickness) in 19 passes using a rolling mill with a roll diameter of $340 \mathrm{~mm}$. The ratio of contact length over average 
thickness $l / h$ was between 0.5 and 5 to ensure a homogenous rolling [26,27]. Mineral oil was applied as lubricant to reduce surface friction.

2.2 Thermal treatment and EBSD characterization for statistical analysis

A series of partially recrystallized samples were prepared by isothermal annealing at $150{ }^{\circ} \mathrm{C}$ from $300 \mathrm{~s}$ to $14400 \mathrm{~s}$ in an air furnace. The microstructures after cold-rolling and after partial recrystallization were characterized on the longitudinal section (defined by the rolling direction (RD) and the normal direction (ND)) using EBSD in a Zeiss-Supra 35 field emission scanning electron microscope. Step sizes from 0.05-2 $\mu \mathrm{m}$ were used depending on the microstructures. For the partially recrystallized samples, two maps covering areas larger than $300 \times 300 \mu \mathrm{m}^{2}$ each were obtained using a step size of $1 \mu \mathrm{m}$ for each annealing time.

Recrystallizing grains within partially recrystallized samples were identified automatically from the EBSD data using an in-house algorithm [28] according to the following three criteria: 1) the internal misorientation within a recrystallizing grain should be less than $1^{\circ}$; 2) the equivalent circular diameter $(E C D)$ of a recrystallizing grain should be larger than $3 \mu \mathrm{m} ; 3)$ a recrystallizing grain should be at least partially surrounded by high angle boundaries (HABs), where HABs are defined as boundaries with misorientation angles larger than $15^{\circ}$. In this work, if not specified, twin boundaries, which developed during recrystallization, were treated as normal HABs in the grain reconstruction process, i.e. twins are considered as individual grains. This choice is because the focus of the present work is on growth kinetics of grains with different orientations.

Parameters considered in the statistical kinetic analysis include: recrystallized volume fraction $V_{V}$, number of recrystallizing grains per unit volume $N_{V}$, and average growth rate of recrystallizing grains $G$. $V_{V}$ was determined as the area fraction of all recrystallizing grains, and the recrystallized fractions of the cube and noncube texture component $\left(V_{V, \text { cube }}\right.$ and $\left.V_{V, \text { noncube }}\right)$ were determined as the area fraction of cube and noncube recrystallizing grains, respectively. $N_{V}$ was calculated using the following equation [29]:

$$
N_{V}=16 V_{V} / 9 \pi L^{3}
$$


where $L$ is the average intercept length of recrystallizing grains determined from the EBSD data. This equation was extended to calculate $N_{V}$ of cube and noncube grains $\left(N_{V, \text { cube }}\right.$ and $\left.N_{V, \text { noncube }}\right)$ by substituting $V_{V}$ and $L$ with $V_{V, c u b e}, L_{\text {cube }}$ and $V_{V \text {,noncube, }} L_{\text {noncube, }}$, respectively. The average growth rates of cube and noncube grains $\left(G_{\text {cube }}\right.$ and $\left.G_{\text {noncube }}\right)$ were calculated using the extended Cahn and Hagel method [30]:

$$
\langle G\rangle_{i}=\left(d V_{V, i} / d t\right) / S_{V, i}
$$

where $i$ represents either cube or noncube, $S_{V, i}$ is the interfacial area between cube/noncube recrystallizing grains and the deformed matrix per unit volume, determined by the line intercept method, and $d V_{V, i} / d t$ is the increase of the volume fraction $d V_{V, i}$ of cube/noncube recrystallizing grains during the time increment $d t$.

\subsection{In situ investigations with 3DXRD}

The recrystallization kinetics of individual grains was measured during in situ annealing using 3DXRD at beamline P07, PETRAIII, Deutsches Elektronen-Synchrotron (DESY). A specimen was cut from the cold-rolled sample with $\sim 2 \mathrm{~mm}$ along RD, $500 \mu \mathrm{m}$ along ND, and $750 \mu \mathrm{m}$ along the transverse direction (TD), and electropolished to avoid nucleation from surface imperfections during the subsequent annealing. The specimen was mounted at a sample stage that can rotate around the vertical axis (the rotation angle is denoted as $\omega$ ), aligned with RD parallel to the vertical axis and with TD parallel to the beam direction for the initial position $\omega=0^{\circ}$.

A monochromatic $50 \mathrm{keV}$ X-ray beam was used to illuminate the specimen. The beam size was $500 \times 500 \mu \mathrm{m}^{2}$, and the illuminated sample volume at $\omega=0^{\circ}$ was thus $500 \times 500 \times 750 \mu \mathrm{m}^{3}$. While annealed at $130{ }^{\circ} \mathrm{C}$ in an X-ray transparent furnace in an inert gas atmosphere, the specimen was rotated around the vertical axis from $0^{\circ}$ to $30^{\circ}$ by sweeping a small $0.5^{\circ}$ interval while acquiring diffraction images. Each $30^{\circ}$ sweep took $5.7 \mathrm{~min}$, which is hence the time resolution of the measurement. The entire measurement took $250 \mathrm{~min}$, and 42 sweeps were conducted. The experimental details are summarized in Table 2.

Before annealing, the diffraction images were composed of Debye-Scherrer rings from the deformation structure, referred as the deformation "background". During annealing, 
recrystallizing grains appeared and formed diffraction peaks on top of the deformation "background" when Bragg conditions were fulfilled. At the same time, the deformation "background" decreased with progressing of recrystallization, as the deformed volume was replaced gradually by the recrystallizing grains. The deformation "background" was determined for each diffraction image by fitting a smooth baseline curve to the radical profile of each diffraction ring. The intensity of a diffraction peak was calculated as the integrated intensity over the entire peak subtracting the intensity from the deformation "background". To check whether a recrystallizing grain was completely inside the illuminated sample volume, the beam size was increased to $600 \times 600 \mu \mathrm{m}^{2}$ every sixth sweep; grains growing out of the illuminated volume were identified and excluded, if the intensities of the peaks increased abruptly as the beam size increased, and dropped when the beam size was back to normal. With this experimental set-up, no information about shapes or positions of recrystallizing grains was available, and it was impossible to know whether a grain had impinged upon others. Therefore, a lower annealing temperature $\left(130^{\circ} \mathrm{C}\right)$ than that for the statistical investigation was used. According to hardness measurements, the specimen was only $\sim 25 \%$ recrystallized at the end of the measurement, and impingement should not be severe.

The diffraction peak of a particular recrystallizing grain was first identified from the diffraction images collected during the last $30^{\circ}$ sweep; the peak was then traced back to diffraction images from earlier sweeps, whereby the increase of the peak intensity during annealing was obtained. The integrated intensity was converted to the grain volume using the method introduced in [20]. For each grain, the equivalent sphere diameter (ESD) was calculated from the grain volume, and the increase of ESD with increasing annealing time was used as the growth curve for each grain. The time corresponding to the first detectable nonzero ESD was considered as the nucleation time for the particular grain. Each growth curve was fitted from the first nonzero point using a spline function; the slope of the fitted curve at any time represented the instantaneous growth rate.

A diffraction peak corresponds to one set of diffracting lattice planes. To identify the full crystallographic orientation of a grain, several diffraction peaks from the grain are required [31]. Since we focus on cube oriented grains, a simple approach was used based on the partial orientation information from a single diffraction peak. Only $\{200\}$ and $\{400\}$ diffraction peaks 
were considered, because such peaks from cube grains can be easily recognized by their positions on the detector. Moreover, other diffraction peaks like $\{111\},\{220\}$ and $\{222\}$ may include contributions from a grain and some of its twins, whereas by using $\{200\}$ and $\{400\}$ diffraction peaks only, this problem is avoided. A diffraction peak was considered as from a cube grain, if the corresponding scattering vector deviated less than $10^{\circ}$ from that expected for the ideal cube orientation. This approach meant that grains with RD or ND close to a $<100>$ direction were considered as cube grains. By checking the orientation data from EBSD measurements of the sample after recrystallization, only a few noncube grains corresponding to a volume fraction of $\sim 2 \%$ were possibly mislabeled as cube grains; the present approach is thus considered acceptable.

\section{Results}

\subsection{Deformed microstructure and texture}

The microstructure after cold-rolling is shown in Figure 2a. On an overall scale, the microstructure is composed of bands with different orientations, separated by HABs. On a smaller scale, each band is composed of cell blocks or lamellae, which resembles those observed in nickel rolled to the same strain [32]. Localized shear bands (LSBs) are observed, but their volume fraction is small. LSBs are most often found in copper oriented $(\{112\}<111>)$ bands, sometimes in $\mathrm{S}$ oriented $(\{123\}<634>)$ bands, but rarely in brass oriented $(\{110\}<112>)$ bands. Unlike macroscopic shear bands, which usually extend through several grains or sometimes the entire sample, LSBs in this sample are typically inside one band. They may distort neighboring bands slightly, but rarely cut through several bands.

The sample develop a typical pure-metal type rolling texture (Figure 2b), and the volume fractions of the three rolling texture components, copper, $\mathrm{S}$ and brass components (within $15^{\circ}$ deviation from the ideal orientations; in cases where an orientation is within $15^{\circ}$ of more than one ideal orientation, the one with smaller deviation is used) are $16 \%, 42 \%$ and $19 \%$, respectively. A small amount of cube texture ( $2 \%$ volume fraction) is observed, which has been seen in cold-rolled copper [4] and other metals [33,34]. The cube oriented regions are usually observed as thin bands (see Figure 2a).

3.2 Statistical analysis of recrystallization kinetics 


\subsubsection{Recrystallized volume fraction}

The recrystallization kinetics is commonly expressed by the Johnson-Mehl-AvramiKolmogorov (JMAK) equation ([35-39]):

$$
V_{V}=1-\exp \left(-k t^{n}\right)
$$

where $k$ and $n$ are parameters describing the kinetics, and $n$ is termed the Avrami exponent. The JMAK equation can be rewritten as:

$\log \left(-\ln \left(1-V_{V}\right)\right)=\log k+n \log t$

The Avrami exponent $n$ can be derived from the slope of an 'Avrami plot': a plot of $-\ln \left(1-V_{V}\right)$ as a function of $t$ on a log-log scale (Figure 3a). However, the data points of the present sample do not follow a single straight line, which suggests that the JMAK equation cannot describe this kinetics. As shown by the dashed curve in Fig. 3a, a better fitting is obtained by adding a second order term in Equation (4), i.e.

$$
\log \left(-\ln \left(1-V_{V}\right)\right)=A+B \log t+C(\log t)^{2}
$$

This equation was suggested in [40] to give a better fit to kinetic data for copper cold-rolled to $92 \%$ thickness reduction, i.e. data similar to the present one. The extra term with $(\log t)^{2}$ does not represent any physical mechanism. The equation is only used to obtain a good fit to the experimental data, and thus a proper determination of growth rates using Equation (2), but not for any interpretation of nucleation or growth phenomena.

For each annealing time, $V_{V \text {,cube }}$ and $V_{V \text {,noncube }}$ are almost equal, and both $V_{V \text {,cube }}$ and $V_{V \text {, noncube }}$ increase linearly with the total $V_{V}$ (Figure $3 b$ ). Such a linear increase of recrystallized cube volume as a function of $V_{V}$ has also been observed in aluminium [41]. However, both oriented nucleation and oriented growth may lead to a linear increase [42], and thus this result does not provide any hint on which mechanism is applicable.

\subsubsection{Number of recrystallizing grains per unit volume}

The number of recrystallizing grains per unit volume $N_{V}$ is calculated using Equation (1). As shown in Figure 4a, when twins are considered as independent grains, $N_{V}$ increases continuously until annealing for about $7200 \mathrm{~s}(\sim 80 \%$ recrystallized). When a parent grain and all its twins are 
considered as a unity, $N_{V}^{*}$ also increases continuously during annealing, but saturates slightly earlier, after $3600 \mathrm{~s}$ annealing ( $\sim 60 \%$ recrystallized). By comparing $N_{V}$ and $N_{V}^{*}$, i.e. considering twins or not, it is seen that no new nuclei form, while more twins appear from $3600 \mathrm{~s}$ to $7200 \mathrm{~s}$. The saturated $N_{V}$ is 5 times larger when twins are considered as independent grains, showing that twinning frequently occurs during recrystallization of this material.

The relative frequency of cube grains, calculated as $N_{V, \text { cube }} /\left(N_{V, \text { cube }}+N_{V, \text { noncube }}\right)$, is $\sim 10 \%$ through the entire recrystallization process (Figure 4b). Compared with the relative frequency of cube grains in a random textured sample, which is $2.5 \%$, this sample has a preference for nucleation of cube grains. However, considering that $V_{V, \text { cube }}$ is $\sim 50 \%$ of the total $V_{V}$ (see Figure $3 b)$, the preferential nucleation of cube grains alone is insufficient to explain the development of the cube texture. Moreover, the relative frequency of cube grains is almost constant during recrystallization, which means that cube grains do not nucleate earlier than noncube grains. It was suggested previously that the deformed matrix of cube orientation recovered faster, which lead to earlier nucleation of cube grains [3,33]. However, effects of this are not evident in the present sample.

\subsubsection{Average growth rates}

Figure 5 shows the average growth rates of cube and noncube grains. The data points for the longest annealing time $14400 \mathrm{~s}$ are not included, because the uncertainty in calculating the CahnHagel growth rates is typically large towards the end of recrystallization [43]. The average growth rates of both cube and noncube grains decrease rapidly with time. Cube grains show a prominent growth advantage, which is most significant at the beginning of recrystallization. On average, the growth rate of cube grains is about twice that of noncube grains. Growth advantage of a similar magnitude has been reported for cube grains for various aluminium alloys and copper [16], and for nickel [44]. This growth advantage is important for the development of cube texture, because a factor of 2 in linear growth rate leads to a factor of $8\left(2^{3}\right)$ in volume growth for $3 \mathrm{D}$ growth.

3.3 Microstructural evolution during recrystallization

3.3.1 Initial stage of recrystallization 
Figure 6 shows a typical microstructure at the initial stage of recrystallization $(8 \%$ recrystallized). The sizes of recrystallizing grains vary significantly: the average grain size, calculated as the average $E C D$, is $5.7 \mu \mathrm{m}$, whereas the largest grain observed in this sample has an ECD of $68 \mu \mathrm{m}$ (marked as Grain A in Figure 6), more than 10 times of the average. Such a broad size distribution is sometimes observed for abnormal grain growth (e.g. [45]), but rarely for recrystallization. Twinning occurs frequently during recrystallization, and as twins are considered as individual grains in this calculation, the average grain size is relatively low due to many small twins. If a grain and all its twins are considered as a unity, the average grain size becomes $11.9 \mu \mathrm{m}$; yet the largest grain size is close to 6 times the average size.

Besides Grain A, several relatively large grains, with ECDs larger than $15 \mu \mathrm{m}$, are observed, most of which are cube grains. The large cube grains share two features: 1) they tend to be elongated along RD; 2) the sizes of their twins are much smaller than the "parent" cube grains, and many of these small twins are surrounded by the "parent" cube grain. The second feature indicates that during the growth of these large cube grains, their twins do not grow as fast as the cube oriented part.

On the other hand, not all cube grains are large, and there are more small cube grains than the large ones. $80 \%$ of the cube grains observed on the longitudinal section are smaller than $15 \mu \mathrm{m}$, and they account for only $22 \%$ area fraction of the recrystallized cube texture.

\subsubsection{Final stage of recrystallization}

After $14400 \mathrm{~s}$ annealing at $150{ }^{\circ} \mathrm{C}$ (the longest annealing time used in this work), the sample is almost fully recrystallized (see Figure 7). The microstructure is composed of a few large grains of similar sizes as Grain A in Figure 6, and of a large number of small grains. Most large grains are cube oriented, resulting in a strong cube texture.

Figure 8 shows the size distribution of cube and noncube grains at this stage. Obviously, the distribution is much broader for cube grains. The width of the size distribution of cube grains may even be under-estimated, because many large cube grains extend outside the mapped area (see Figure 7). The large cube grains are small in number fraction (Figure 8a), but large in area fraction (Figure 8b). In other words, a few large cube grains are dominating the cube texture. To quantify the contribution from large cube grains, we define cube grains with a size larger than 5 
times the median size of cube grains as supercube grains, i.e. cube grains with $E C D s>33 \mu \mathrm{m}$ are called supercube grains. With this definition, $5 \%$ of the cube grains in the characterized section are supercube grains, and they contribute to $58 \%$ of the total cube area.

\subsection{Recrystallization kinetics of supercube grains and other cube grains}

Why a few cube grains become supercube grains is the key to explain the development of cube texture and the broad grain size distribution in this sample. Various scenarios may lead to a larger grain size: 1) earlier nucleation, 2) higher growth rates, and 3) growth rates that decrease more slowly due to for example less impingement. To test if any of these scenarios are applicable, we need to follow the growth of individual grains in situ during annealing, which is at present only possible using 3DXRD. An extra benefit using 3DXRD is that such measurements provide real grain sizes in $3 \mathrm{D}$, which complements the sizes measured from $2 \mathrm{D}$ maps.

The in situ 3DXRD measurement was conducted at $130{ }^{\circ} \mathrm{C}$ for $250 \mathrm{~min}$. In total, 825 growth curves are identified, out of which 101 are from cube grains. The size distribution of cube grains at the end of the measurement (corresponding to $\sim 25 \%$ recrystallization) is plotted in Figure 9, in a similar way as Figure 8, but replacing area fraction and $E C D$ with volume fraction and $E S D$, respectively. In agreement with the results from EBSD characterization in 2D, cube grains measured in 3D also have a broad size distribution, and a few large grains contribute significantly to the total cube volume. Following the definition of supercube grains in Section 3.3.2 $(E C D s>33 \mu \mathrm{m})$, the minimum $E S D$ of supercube grains is defined by simply multiplying the stereological coefficient $4 / \pi$, i.e. $33 \cdot 4 / \pi=42 \mu \mathrm{m}$. It has to be noted that here we adopt the definition of supercube grains from fully recrystallized samples, which is a conservative choice since the in situ annealed sample is only $\sim 25 \%$ recrystallized. However, according to the growth curves (Figure 10), growth rates decrease quickly for most grains, and therefore, except a few small cube grains that nucleate just before the end of the measurement, most small cube grains are unlikely to become supercube grains in case the annealing continues. With this definition, 16 grains are classified as supercube grains, which account for $16 \%$ of all cube grains, and represent $72 \%$ of the total cube volume. The grain sizes measured using 3DXRD confirm that supercube grains and the broad size distribution of cube grains are not 2D artifacts, and that the appearance 
of supercube grains is unaffected by the change of the annealing temperature $\left(150{ }^{\circ} \mathrm{C}\right.$ and $130{ }^{\circ} \mathrm{C}$ for EBSD and 3DXRD characterizations, respectively).

Five typical growth curves for supercube grains and for other cube grains are plotted in Figure 10. For both supercube and other cube grains, some grains appear at the beginning of recrystallization, whereas some show an incubation time longer than $150 \mathrm{~min}$. The largest supercube grain has an incubation time of $\sim 40 \mathrm{~min}$. The average nucleation time for all observed supercube grains is $58 \mathrm{~min}$, slightly smaller than that for other cube grains (74 min). We compared the distributions of nucleation times of supercube grains and other cube grains using the Kolmogorov-Smirnov test [46], and obtained a $p$-value of 0.22 . According to statistics, two distributions are considered significantly different if the $p$-value is below 0.05 . Therefore, statistically speaking, supercube grains do not nucleate significantly earlier than other cube grains, and Scenario 1 listed above is therefore not applicable.

The increase of grain sizes $(E S D)$ does not follow a straight line, i.e. the growth rates vary with time (Figure 10). For most growth curves, the increase of grain sizes is fastest at the beginning, and slows down afterwards. Compared with other cube grains, growth rates of supercube grains are much higher. The dependence between sizes and growth rates for cube grains is illustrated in Figure 11, where the maximal growth rate on a growth curve is used to represent the growth rate of the grain. The grains which are large at the end of the in situ measurement tend to grow with higher growth rates, although the maximal growth rates vary for grains with similar final grain sizes. The largest supercube grain is found to have the highest maximal growth rate. Therefore, Scenario 2, higher growth rates for supercube grains, is supported by the experimental results.

In Figure 10, the groups of curves for supercube and for other cube grains resemble each other, if the scale of the $y$ axis is ignored. Thus Scenario 3, growth rates of supercube grains decreasing more slowly compared with other cube grains, is not supported by the experimental data.

\section{Discussion}

By statistical kinetics analysis using EBSD data, we quantified the importance of oriented nucleation and oriented growth: the frequency of cube grains is 4 times that for random 
nucleation during the entire recrystallization; the average growth rate of cube grains is about twice that of noncube grains. By measuring in situ kinetics for individual grains using 3DXRD, the growth rates of cube grains are found to be non-uniform: supercube grains grow with higher growth rates than other cube grains, whereby they reach large sizes, and become the major contributor to the cube texture after recrystallization. These findings extend the understanding of oriented growth: a higher average growth rate of a texture component can originate from the behavior of only a few grains of this orientation. The findings from 3DXRD raise a new question: why do supercube grains grow with higher growth rates than other cube grains? The 3DXRD data alone are not sufficient to answer this question. But by combining the results with that of EBSD, a further analysis is possible. In the following we will discuss the growth of supercube grains from the aspects of grain orientations, misorientations to the deformed matrix, and other properties of the deformed matrix.

\subsection{Orientations}

The first hypothesis is that cube grains with orientations closer to the ideal cube orientation have a better growth condition [47]. To test this hypothesis, the grain sizes from the EBSD investigations are plotted as a function of the orientation deviation from the ideal cube orientation for all the cube grains for the sample annealed at $150{ }^{\circ} \mathrm{C}$ for $14400 \mathrm{~s}(85 \%$ recrystallized) (Figure 12). To avoid the possible 2D artifact that a small cube grain seen on the characterized section may be a part of a supercube grain in $3 \mathrm{D}$, small cube grains with orientations less than $1^{\circ}$ from a nearby supercube grain are excluded. Small cube grains at the edge of the mapped area are also excluded, because we cannot decide whether they are truly small or belong to a supercube grain beyond the mapped area. Among the supercube grains, 94\% are oriented within $10^{\circ}$ from the ideal cube orientation, and $38 \%$ are within $5^{\circ}$, whereas among the other cube grains, $70 \%$ and $16 \%$ are oriented within $10^{\circ}$ and $5^{\circ}$ deviation, respectively. Supercube grains appear to be oriented slightly closer to the ideal cube orientation. However, the two grains with an orientation closest to the ideal cube are not supercube grains. Therefore, deviations from the ideal cube orientation do not seem to explain the different growth rates of the two groups of cube grains.

4.2 Misorientations 
The second hypothesis leading to higher growth rates is a preferred misorientation of cube grains to the deformed matrix, as suggested in the oriented growth mechanism [1]. To test this hypothesis, we calculated independently the misorientations of supercube grains and other cube grains to their neighboring deformed matrix based on the EBSD data of the sample annealed at $150{ }^{\circ} \mathrm{C}$ for $1200 \mathrm{~s}$ ( $19 \%$ recrystallized, including 6 supercube grains). Both misorientation angle distributions, as plotted in Figure 13, peak at $50^{\circ}-55^{\circ}$. The misorientation axes for supercube grains are more concentrated around a pole near $\langle 111\rangle$, but shifted towards $\langle 110\rangle$, while other cube grains have a wider distribution of misorientation axes. The fractions of $\sum 7$ boundaries (using the Brandon criterion) or $40^{\circ}<111>$ misorientations are only $3 \%$ for both supercube and other cube grains. Although not identical to each other, the misorientations to the neighboring deformed matrix for supercube grains and other cube grains are not considered to support the hypothesis.

The approach above, however, has the disadvantage of "destroyed evidence" [4]: the deformed matrix favorable for growth has been invaded. This is even more problematic for the present study, because supercube grains can only be distinguished after reaching a certain size, and the growth curves in Figure 10 show that the growth rates are typically highest at the initial growth stage. Therefore, the neighboring deformed matrix of a supercube grain observed in a partially recrystallized structure is not the one that has contributed to the initial high growth rates. On the contrary, some of the neighboring matrix may be unfavorable for growth, and therefore, left uninvaded.

To avoid the "destroyed evidence" problem, we did an ex situ EBSD experiment, and mapped an area on the longitudinal section before and after $35 \mathrm{~min}$ annealing at $150{ }^{\circ} \mathrm{C}$. One cube grain with an $E C D$ of $29 \mu \mathrm{m}$ was observed after annealing (Figure 14b). This grain is considered as a supercube grain, because its morphology is similar to those supercube grains in Figures 6 and 7 , although the grain size is slightly smaller than $33 \mu \mathrm{m}$, required by the definition. The map taken before annealing includes most of the deformed matrix invaded by this supercube grain; this invaded region is shown separately in Figure 14c.

As shown in Figure 15, the distribution of misorientation angles of this supercube grain to the invaded matrix peaks at $45^{\circ}-50^{\circ}$, and the misorientation axes concentrate close to $<111>$. Also in this distribution, the $40^{\circ}<111>$ or $\sum 7$ misorientation is rare. But the difference between Figure 
15 and Figure 13 suggests that supercube grains grow preferentially into deformed matrix of some particular orientations, and leave other parts uninvaded. The preferential growth into some orientations is also obvious from the morphology of the supercube grain. As shown in Figure 14, this supercube grain grows into bands that belong to different texture components, and the growth in different bands is not uniform. The two large protrusions (marked by ellipses in Figure 14b) show where preferential growth has occurred. Both protrusions are located at S oriented deformed matrix. As discussed in earlier work, preferential growth into $\mathrm{S}$ orientations may be related to either misorientations near (although not exactly at) $40^{\circ}<111>$ [4] or higher stored energy within $\mathrm{S}$ oriented bands [49]. If the preferential growth is due to higher stored energy within $\mathrm{S}$ oriented bands, it would be expected that twins of the supercube grains would grow equally well into these $\mathrm{S}$ oriented bands, which is not observed experimentally for supercube grains in this sample. Therefore, the preferential growth should more likely be attributed to the misorientation relationship to $\mathrm{S}$ orientations .

\subsection{Local microstructure}

Another observation from Figure 14 is that the local spatial distribution of $\mathrm{S}$ oriented bands affects the growth into less favorable bands, and thus the growth of the entire grain. The invaded matrix contains several S oriented bands (Figure 14c): most of them cluster in the lower part, separated only by thin bands $(<1 \mu \mathrm{m}$ thick) of non-S orientations. Our interpretation of the growth into such a band-like deformation microstructure is illustrated by an idealized sketch in Figure 16. When a grain simultaneously grows into several bands, protrusions form where the growth occurs at favorable bands, whereas retrusions form at the less favorable bands. The boundary curvatures in the retrusions provide an extra driving force for growth [50]. If a less favorable band is narrow, the boundary curvature of the retrusion is large, which results in a large extra driving force and faster growth [51]. This may be the situation in the lower part of Figure 14b. However, if the less favorable band is wide, the extra driving force from the boundary curvatures is small and insufficient to drive the boundary through the band, and the growth will be slow, like the retrusion marked by the arrow in Figure 14b. It is therefore suggested that the higher growth rates of supercube grains are closely related to not only the misorientations, but also the morphology of the local deformation microstructure into which the grains grow. 


\section{Conclusions}

The microstructural and textural evolution during recrystallization of $90 \%$ cold-rolled oxygen free high conductivity copper was investigated using EBSD and 3DXRD.

1) Statistical analysis based on EBSD data shows that the recrystallized cube texture in the investigated material relates to combined oriented nucleation and oriented growth, of which oriented growth plays the dominating role.

2) Only a small fraction of cube grains grow preferentially by oriented growth. These grains become super large, and as a consequence, the recrystallized microstructure has a broad grain size distribution. These large cube grains are called supercube grains, and contribute significantly to the cube texture development during recrystallization in the present material.

3) In analyzing why only some cube grains grow to become supercube grains, whereas many other cube grains are of similar sizes as non-cube grains, it is found that supercube grains grow at higher growth rates, but they do not have orientations closer to the ideal cube orientation compared with other cube grains. The distributions of nucleation times of supercube grains and other cube grains are not statistically significantly different either.

4) The higher growth rates of the supercube grains are related to preferential growth into $S$ oriented bands with misorientations around $45^{\circ}-50^{\circ}<111>$. It is however suggested that not only the misorientation but also the morphology of the neighboring deformed microstructure contribute to the fast boundary migration of the supercube grains.

\section{Acknowledgements}

The authors gratefully acknowledge the support from the Danish National Research Foundation (Grant No. DNRF86-5) and the National Natural Science Foundation of China (Grant No. 51261130091) to the Danish-Chinese Center for Nanometals, within which this work has been performed. The authors also acknowledge beamtime by DESY under proposal number I-20110560 EC. Drs. N. Schell and S.O. Poulsen are gratefully thanked for their help with the 3DXRD investigations.

\section{References}

[1] P.A. Beck, Acta Metall. 1 (1953) p.230. 
[2] I.L. Dillamore and H. Katoh, Metal Sci. 8 (1974) p.73.

[3] A.A. Ridha and W.B. Hutchinson, Acta Metall. 30 (1982) p.1929.

[4] B.J. Duggan, K. Lücke, G. Kohlhoff and C.S. Lee, Acta Metall. Mater. 41 (1993) p.1921.

[5] G. Wassermann and J. Grewen, Texturen metallischer Werkstoffe, Springer-Verlag, Berlin, 1962.

[6] O. Engler, Acta Mater. 49 (2001) p.1237.

[7] Ph. Gerber, J. Tarasiuk, Th. Chauveau and B. Bacroix, Acta Mater. 51 (2003) p.6359.

[8] S.H. Hong and D.N. Lee, Mater. Sci. Eng. A 351 (2003) p.133.

[9] Ph. Gerber, T. Baudin, R. Chiron and B. Bacroix, Mater. Sci. Forum 495-497 (2005) p.1303.

[10] N. Takata, K. Yamada, K. Ikeda, F. Yoshida, H. Nakashina and N. Tsuji, Mater. Sci. Forum 503-504 (2006) p.919.

[11] F.X. Lin, W. Pantleon, T. Leffers and D. Juul Jensen, Mater. Sci. Forum 702-703 (2012) p.398.

[12] R.A. Vandermeer and B.B. Rath, Metall. Trans. A 20 (1989) p.391.

[13] R.A. Vandermeer and D. Juul Jensen, Metall. Mater. Trans. 26A (1995) p.2227.

[14] W. Xu and M. Ferry, Mater. Sci. Technol. 26 (2010) p.333.

[15] E. Jägle and E. J. Mittemeijer, Metal. Mater. Trans. A 43 (2012) p.1117.

[16] D. Juul Jensen, Acta Metall. Mater. 43 (1995) p.4117.

[17] I. Samajdar and R.D. Doherty, Acta Mater. 46 (1998) p.3145.

[18] E.M. Lauridsen, D. Juul Jensen and H.F. Poulsen, Scr. Mater. 43 (2000) p.561.

[19] E.M. Lauridsen, H.F. Poulsen, S.F. Nielsen and D. Juul Jensen, Acta Mater. 51 (2003) p.4423.

[20] S.O. Poulsen, E.M. Lauridsen, A. Lyckegaard, J. Oddershede, C. Gundlach, C. Curfs and D. Juul Jensen, Scr. Mater. 64 (2011) p.1003.

[21] G.L. Wu and D. Juul Jensen, Phil. Mag. 92 (2012) p.3381. 
[22] R.B. Godiksen, S. Schmidt and D. Juul Jensen, Scr. Mater. 57 (2007) p.345.

[23] R.A. Vandermeer, E.M. Lauridsen and D. Juul Jensen, Mater. Sci. Forum 467-470 (2004) p.197.

[24] E.M. Lauridsen, S. Schmidt, S.F. Nielsen, L. Margulies, H.F. Poulsen and D. Juul Jensen, Scr. Mater. 55 (2006) p.51.

[25] L. Kestens and J.J. Jonas, Metall. Mater. Trans. A 27 (1996) p.155.

[26] W. Truszkowski, J. Krol and B. Major, Metall. Trans. A 11 (1980) p.749.

[27] O.V. Mishin, B. Bay, G. Winther and D. Juul Jensen, Acta Mater. 52 (2004) p.5761.

[28] G.L. Wu and D. Juul Jensen, Mater. Charact. 59 (2008) p.794.

[29] E.E. Underwood, Quantitative stereology, Addison-Wesley, 1970.

[30] D. Juul Jensen, Scr. Metal. 27 (1992) p.533.

[31] E.M. Lauridsen, S. Schmidt, R.M. Suter and H.F. Poulsen, J. Appl. Crystllogr. 34 (2001) p.744.

[32] D.A. Hughes and N. Hansen, Metal. Trans. A 24 (1993) p.2021.

[33] S. Zaefferer, T. Baudin and R. Penelle, Acta Mater. 49 (2001) p.1105.

[34] M.H. Alvi, S.W. Cheong, J.P. Suni, H. Weiland and A.D. Rollett, Acta Mater. 56 (2008) p.3098.

[35] W.A. Johnson and R.F. Mehl, Trans. AIME 135 (1939) p.416.

[36] M.J. Avrami, Chem.Phys. 7 (1939) p.1103.

[37] M.J. Avrami, Chem.Phys. 8(1940) p.212.

[38] M.J. Avrami, Chem.Phys. 9 (1941) p.177.

[39] A.N. Kolmogorov, izv. Akad. Nauk. USSR-Ser. Matemat. 1 (1937) p.355.

[40] R.A. Vandermeer and D. Juul Jensen, Scr. Metall. Mater. 30 (1994) p.1575.

[41] R.A. Vandermeer and D. Juul Jensen, Textures and Microstructures 27 (1996) p.263. 
[42] R.D. Doherty, Scr. Metall. 19 (1985) p.927.

[43] R.A. Vandermeer and D. Juul Jensen, Interface Sci. 6 (1998) p.95.

[44] X.L. Li, W. Liu, A. Godfrey, D. Juul Jensen and Q. Liu, Acta Mater. 55 (2007) p.3531.

[45] S.S. Hazra, E. Pereloma and A.A. Gazder, Acta Mater. 59 (2011) p.4015.

[46] E.L. Lehmann and J.P. Romano, Testing statistical hypotheses, Springer, New York 2005.

[47] O. Engler, Acta Mater. 46 (1998) p.1527.

[48] Y.B. Zhang, A. Elbrønd, F.X. Lin, Mater. Charac. 96 (2014) p.158.

[49] I. Samajdar and R.D. Doherty, Scr. Metall. Mater. 32 (1995) p.845.

[50] Y.B. Zhang, A. Godfrey and D. Juul Jensen, Scr. Mater. 64 (2011) p.331.

[51] N. Moelans, A. Godfrey, Y.B. Zhang and D. Juul Jensen, Phys. Rev. B 88 (2013) p.054103. 
Figure and table captions:

Figure 1. Microstructure and texture of the starting material, determined using EBSD with a step size of $2 \mu \mathrm{m}$. (a) Grain boundary map. The black, gray and blue lines represent boundaries with misorientation angles larger than $15^{\circ}, 2^{\circ}$ and twin boundaries, respectively. (b) $\{111\}$ pole figure. Contour levels (1, 2 of multiples of uniform density) are obtained by smoothing with a Gaussian distribution of $5^{\circ}$ half width.

Figure 2. Microstructure and texture after cold-rolling to a strain $\varepsilon_{v M}=2.7$. (a) Orientation map determined using EBSD with a step size of $50 \mathrm{~nm}$. The colors represent the texture components. For the rolling texture component ( $\mathrm{S}$, brass and copper), a maximum deviation of $10^{\circ}$ is used to avoid overlap between different texture components, while for the cube texture, the usual definition of a maximum deviation of $15^{\circ}$ is used. Some typical localized shear bands (LSBs) are marked by arrows. (b) $\{111\}$ pole figure deduced from EBSD data covering an area of $\sim 200$ $\times 200 \mu \mathrm{m}^{2}$ using a step size of $0.5 \mu \mathrm{m}$. Contour levels $(1,2,5,8$ of multiples of uniform density) are obtained by smoothing with a Gaussian distribution of $5^{\circ}$ half width.

Figure 3. Evolution of recrystallized volume fraction, $V_{V}$, for the series of samples annealed isothermally at $150{ }^{\circ} \mathrm{C}$. (a) Avrami plot of the kinetics: $-\ln \left(1-V_{V}\right)$ as a function of annealing time $t$. The straight line shows a fit to the JMAK equation (Equation (4)), whereas the dashed curve shows a better fit using a modified equation (Equation (5)). (b) Volume fractions of recrystallizing cube and noncube grains as a function of the total recrystallized volume fraction.

Figure 4. Nucleation for the series of samples annealed at $150{ }^{\circ} \mathrm{C}$. (a) Evolution of number of recrystallizing grains per unit volume $N_{V}$, determined from EBSD data using Equation (1). For measuring the intercept length of recrystallizing grains, twin boundaries are either considered as normal high angle boundaries (noted as CTB) or ignored (noted as ITB). Twins are considered as individual grains when the CTB method is used, whereas a grain and all its twins are considered as a unity when the ITB method is used. (b) Relative frequency of recrystallizing cube and noncube grains, $N_{V, \text { cube }} /\left(N_{V, \text { cube }}+N_{V, \text { noncube }}\right)$ and $N_{V, \text { noncube }} /\left(N_{V, \text { cube }}+N_{V, \text { noncube }}\right)$, as a function of $t$. Twin boundaries are considered as normal high angle boundaries for determining $N_{V, c u b e}$ and $N_{V, \text { noncube }}$. 
Figure 5. Cahn-Hagel $(\mathrm{C}-\mathrm{H})$ growth rates for the samples annealed isothermally at $150{ }^{\circ} \mathrm{C}$, calculated from EBSD data using Equation (2). The data points for the sample annealed for $14400 \mathrm{~s}$ are not included due to large uncertainty in $\mathrm{S}_{\mathrm{V}}$.

Figure 6. Partially recrystallized microstructure ( $8 \%$ recrystallized) from the sample annealed at $150{ }^{\circ} \mathrm{C}$ for $600 \mathrm{~s}$, characterized using EBSD with a step size of $1 \mu \mathrm{m}$. (a) Boundary map with cube oriented regions shown in red. The black, gray and blue lines represent boundaries with misorientation angles larger than $15^{\circ}, 2^{\circ}$ and twin boundaries, respectively. (b) Map highlighting all the recrystallizing grains using a random color for each recrystallizing grain. The deformed matrix is shown in black. The largest grain is marked as Grain A. The small black holes inside Grain A noticeable in (b) are twins of the grain, which are not considered as recrystallized regions due to their small sizes.

Figure 7. Almost fully recrystallized microstructure (85\% recrystallized) and texture from the sample annealed at $150{ }^{\circ} \mathrm{C}$ for $14400 \mathrm{~s}$, characterized using EBSD with a step size of $1 \mu \mathrm{m}$. (a) Boundary map with cube oriented regions shown in red. The black, gray and blue lines represent boundaries with misorientation angles larger than $15^{\circ}, 2^{\circ}$ and twin boundaries, respectively. (b) Map highlighting all the recrystallizing grains using a random color for each grain. The remaining deformed matrix is shown in black. (c) $\{111\}$ pole figure. Contour levels $(1,2,5,8$, 20, 30 of multiples of uniform density) are obtained by smoothing with a Gaussian distribution of $5^{\circ}$ half width.

Figure 8. Size distributions of 335 cube grains and 2286 noncube grains after annealing at 150 ${ }^{\circ} \mathrm{C}$ for $14400 \mathrm{~s}(85 \%$ recrystallized), determined from EBSD data. Grain sizes are represented as equivalent circular diameters $(E C D s)$. a) Number-weighted size distributions. b) Area-weighted size distributions. In both (a) and (b), the histograms show the fractions of grains of different sizes, and the curves represent the cumulative fractions. Because the minimum size of a recrystallizing grain is defined to be $3 \mu \mathrm{m}$; the first bin $(0-5 \mu \mathrm{m})$ in each histogram is not a complete bin. The minimum ECD for supercube grains $(33 \mu \mathrm{m})$ is marked by arrows.

Figure 9. Size distribution of 101 cube grains after annealing at $130{ }^{\circ} \mathrm{C}$ for $250 \mathrm{~min}(\sim 25 \%$ recrystallized), determined from 3DXRD measurement. Grain sizes are represented as equivalent sphere diameters $(E S D s)$. (a) Number-weighted size distribution. (b) Volume-weighted size 
distribution. In both (a) and (b), the histograms show the fractions of grains of different sizes, and the curves represent the cumulative fractions. The minimum ESD for supercube grains (42 $\mu \mathrm{m})$ is marked by arrows.

Figure 10. A selection of growth curves for supercube grains (a) and other cube grains (b) measured using 3DXRD during in situ annealing at $130{ }^{\circ} \mathrm{C}$. The sample is $\sim 25 \%$ recrystallized at the end of the measurement (after $\sim 250$ min annealing). The scales of the $y$ axis of the two plots are different.

Figure 11. The maximal growth rate observed on each growth curve as a function of the grain size (at the end of the 3DXRD measurement) for all cube grains. Large grains tend to have higher maximal growth rates; this tendency is illustrated by the dashed line.

Figure 12. Sizes of recrystallizing cube grains as a function of the deviation from the ideal cube orientation for the sample annealed at $150{ }^{\circ} \mathrm{C}$ for $14400 \mathrm{~s}(85 \%$ recrystallized), calculated from EBSD data.

Figure 13. Misorientations of supercube and other cube grains to their neighboring deformed matrix after annealing at $150{ }^{\circ} \mathrm{C}$ for $1200 \mathrm{~s}$. (a) Misorientation angle distribution. (b) Inverse pole figures (IPFs) showing the distributions of the misorientation axes. Contour levels are 1, 2, 3 of multiples of uniform density.

Figure 14. Orientation maps before (a) and after (b) $150{ }^{\circ} \mathrm{C}$ annealing for $35 \mathrm{~min}$, showing a region where a supercube grain is observed. An affine transformation has been applied to the map in (a) for a better correlation with the map in (b) [48]. The supercube grain has grown out of the region characterized before annealing, but the major part of the invaded deformed matrix is revealed, and is shown separately in (c). The colors represent texture components. For the rolling texture components ( $\mathrm{S}$, brass and copper), a maximum deviation of $10^{\circ}$ is used to avoid overlap between different texture components, whereas for the cube texture, the usual definition of a maximum deviation of $15^{\circ}$ is used. The black spots in (b) are non-indexed regions due to surface contamination. In (b), the ellipses mark two protrusions, where the growth rate has been higher, and the arrow marks a retrusion, where the growth lags behind.

Figure 15. Misorientations of the supercube grain shown in Figure $14 \mathrm{~b}$ to the deformed matrix it has invaded during its growth after annealing at $150{ }^{\circ} \mathrm{C}$ for $35 \mathrm{~min}$. (a) Misorientation angle 
distribution. (b) IPF showing the distributions of the misorientation axes. Contour levels are 1, 2, 3 of multiples of uniform density.

Figure 16. Schematic diagrams illustrating fast growth in a band-like deformed microstructure with different band width, as typically seen experimentally. The gray bands in the deformed matrix are favorable for growth, whereas the white bands are unfavorable. (a) An imaginary recrystallizing grain shown in red is growing into several bands. (b) The migration distances into favorable and unfavorable bands are different. Retrusions thus form at the unfavorable bands. The curvatures of the retrusions are larger at narrow bands. (c) The migration distance in the unfavorable bands increases because of the extra driving forces from boundary curvatures at retrusions. The migration distance is larger where the boundary curvature is larger. The narrower an unfavorable band is, the easier it can be invaded.

Table 1. Chemical composition (wt. \%) of the copper used in this work.

Table 2. Experimental details of the 3DXRD experiment. 
Table 1. Chemical composition (wt. \%) of the copper used in this work.

\begin{tabular}{llll}
\hline $\mathrm{Cu}(\%)$ & $\mathrm{Ni}(\%)$ & $\mathrm{Mg}(\%)$ & $\mathrm{Al}(\%)$ \\
\hline Balance & 0.002 & 0.002 & 0.002 \\
\hline "Elements & $<0.001 \%: \mathrm{Zn}, \mathrm{Pb}, \mathrm{Sn}, \mathrm{P}, \mathrm{Mn}, \mathrm{Fe}, \mathrm{Si}, \mathrm{Cr}, \mathrm{As}$
\end{tabular}

Table 2. Experimental details of the 3DXRD experiment.

\begin{tabular}{ll}
\hline Beam size & $500 \times 500 \mu \mathrm{m}^{2}$ \\
\hline X-ray energy & $50 \mathrm{keV}$ monochromatic \\
\hline 2D detector & $\begin{array}{l}2048 \times 2048 \text { pixels } \\
\text { Pixel size } 200 \times 200 \mu \mathrm{m}^{2}\end{array}$ \\
\hline Distance between sample and detector & $592 \mathrm{~mm}$ \\
\hline Rotation range of sample stage $(\omega)$ & $0^{\circ}$ to $30^{\circ}$ \\
\hline Rotation interval & $0.5^{\circ}$ \\
\hline Exposure time & $0.5 \mathrm{~s}$ \\
\hline Time resolution & 5.7 minutes \\
\hline
\end{tabular}




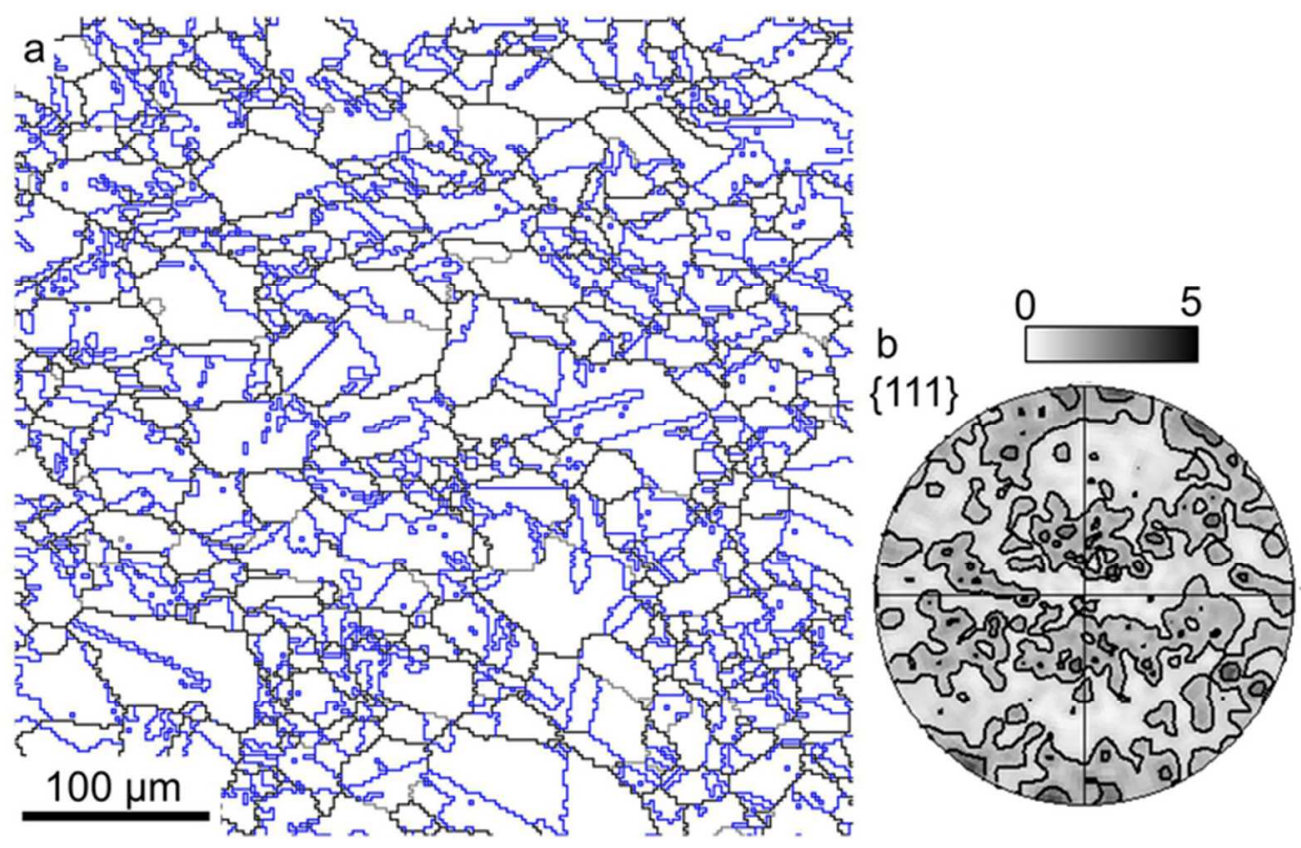

Figure 1

$63 \times 40 \mathrm{~mm}(300 \times 300 \mathrm{DPI})$ 


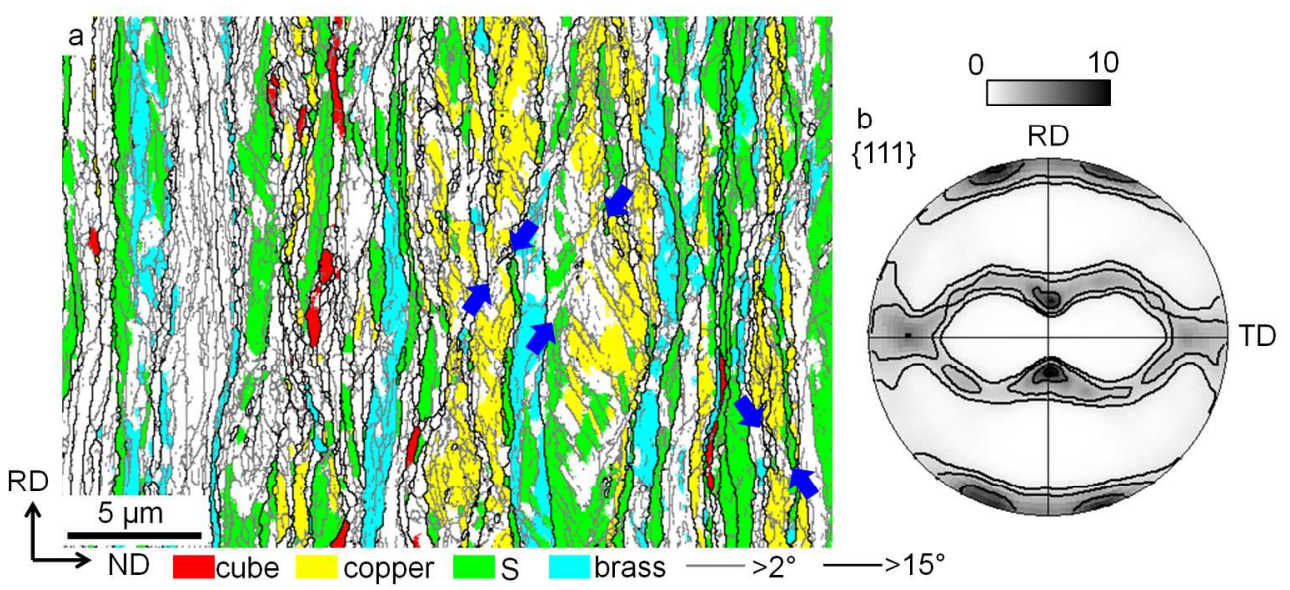

Figure 2

$747 \times 345 \mathrm{~mm}(72 \times 72$ DPI $)$ 


1
2
3
4
5
6
7
8
9
10
11
12
13
14
15
16
17
18
19
20
21
22
23
24
25
26
27
28
29
30
31
32
33
34
35
36
37
38
39
40
41
42
43
40
45
49
50
51
52
53
55
50

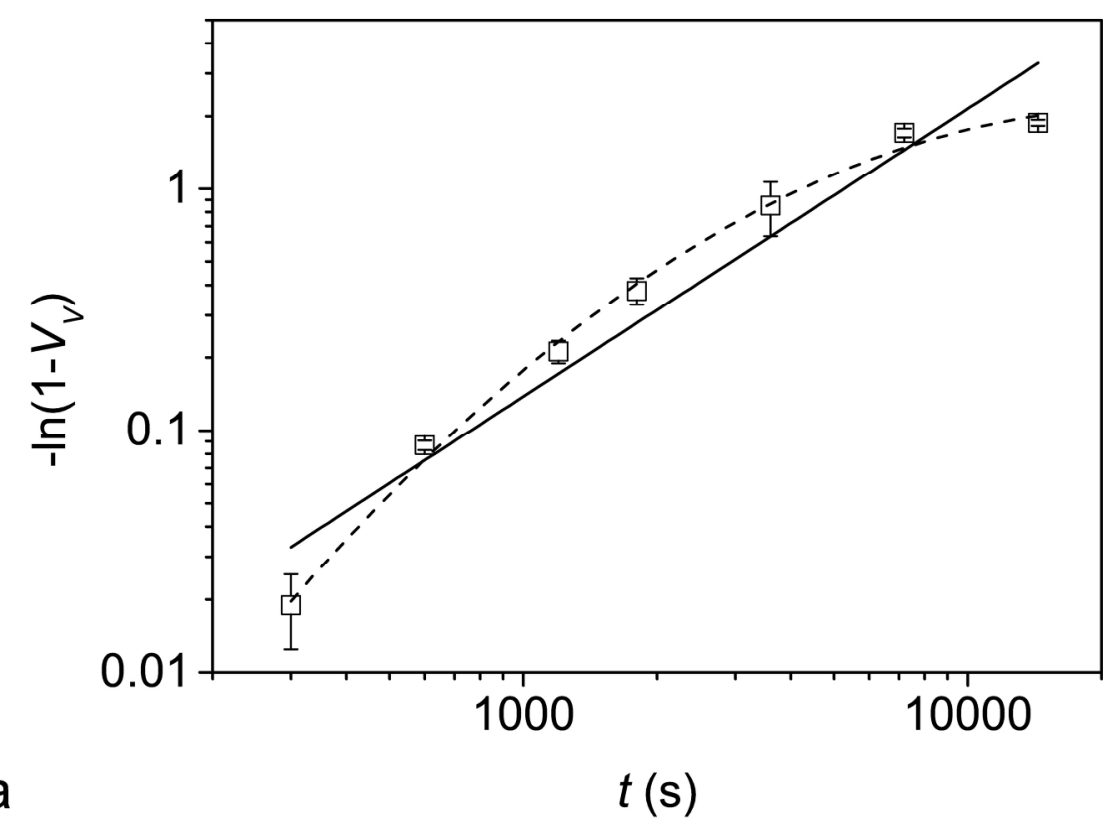

Figure $3 a$

$201 \times 140 \mathrm{~mm}(300 \times 300$ DPI) 


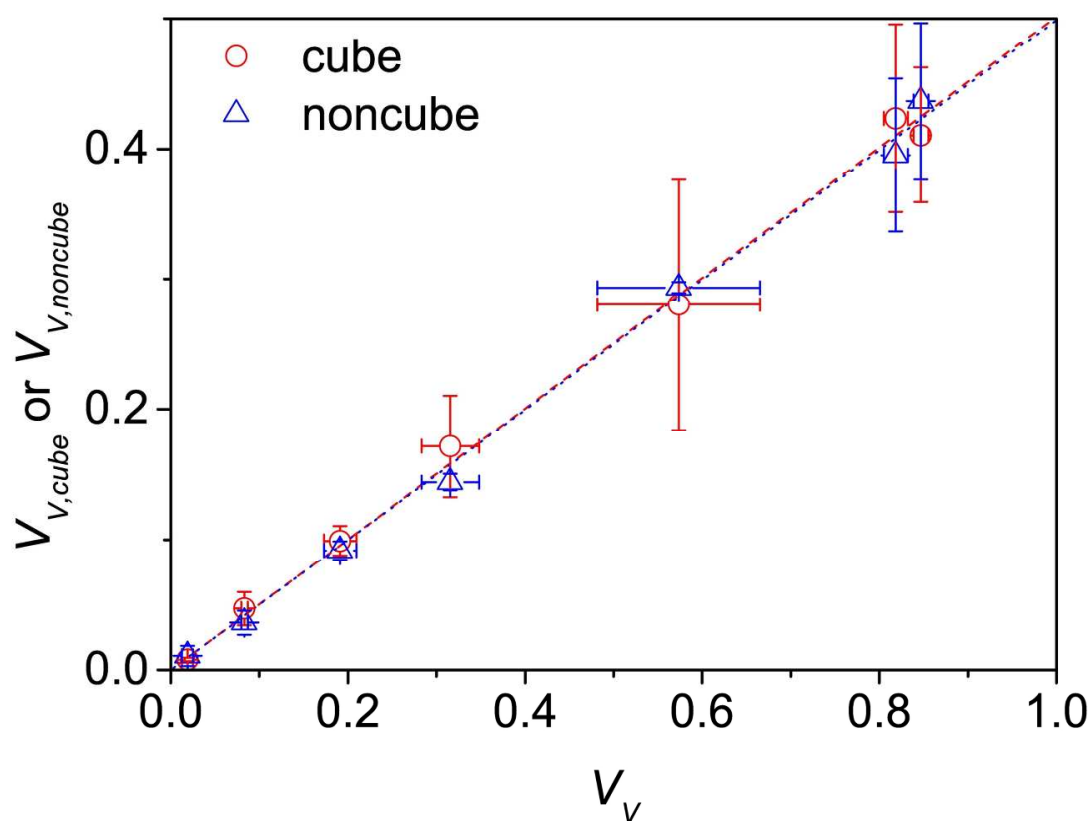

Figure $3 \mathrm{~b}$

$201 \times 140 \mathrm{~mm}(300 \times 300$ DPI $)$ 


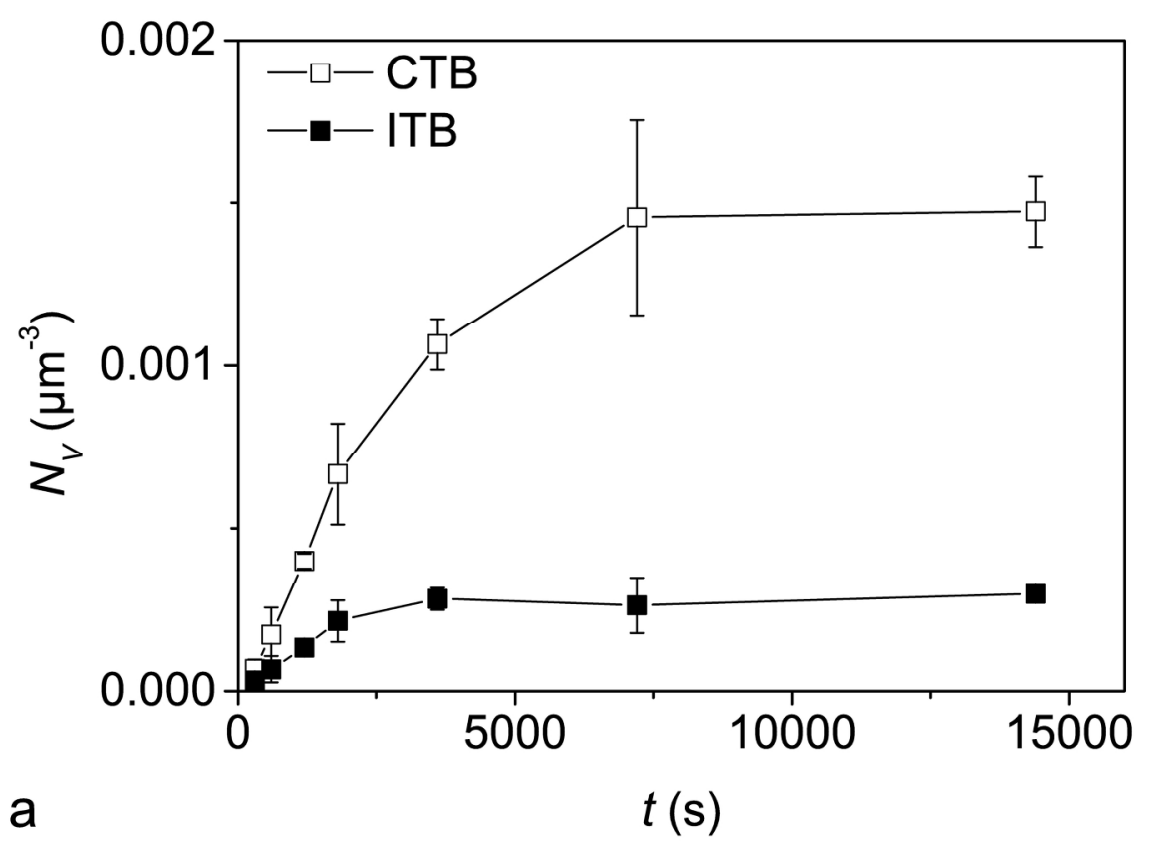

Figure $4 a$

$201 \times 140 \mathrm{~mm}(300 \times 300$ DPI $)$ 


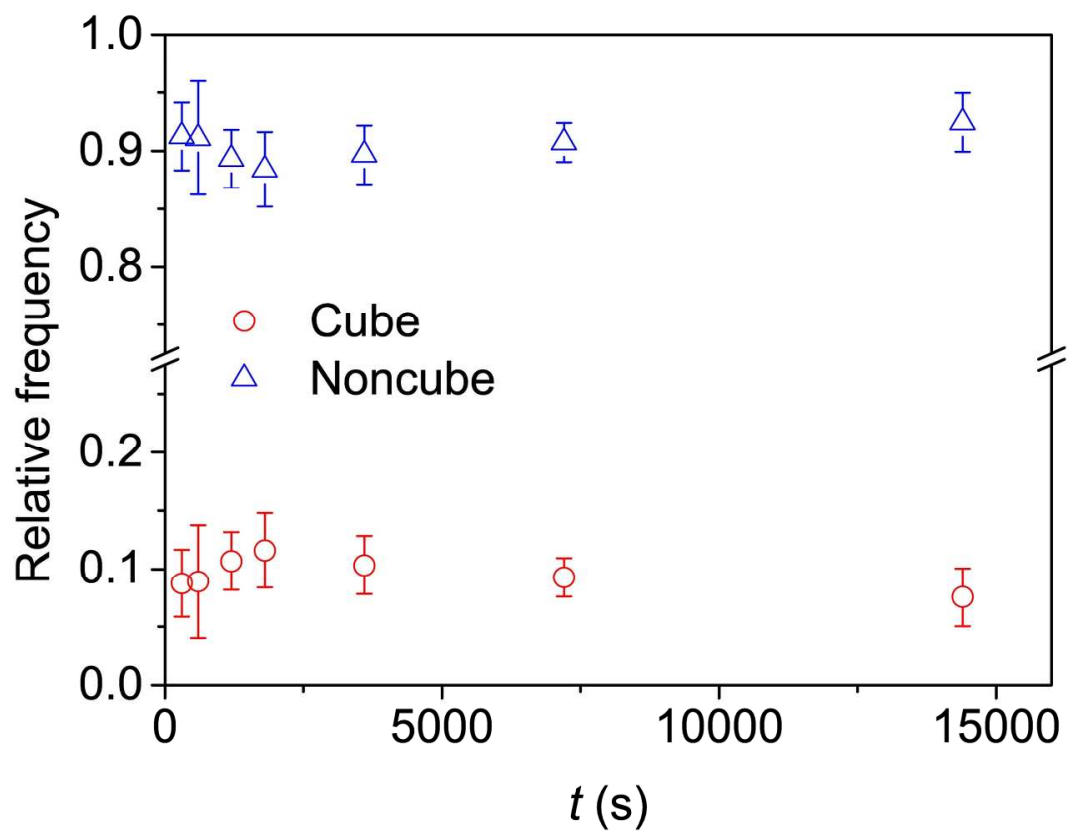

Figure $4 b$

$201 \times 140 \mathrm{~mm}(300 \times 300$ DPI) 


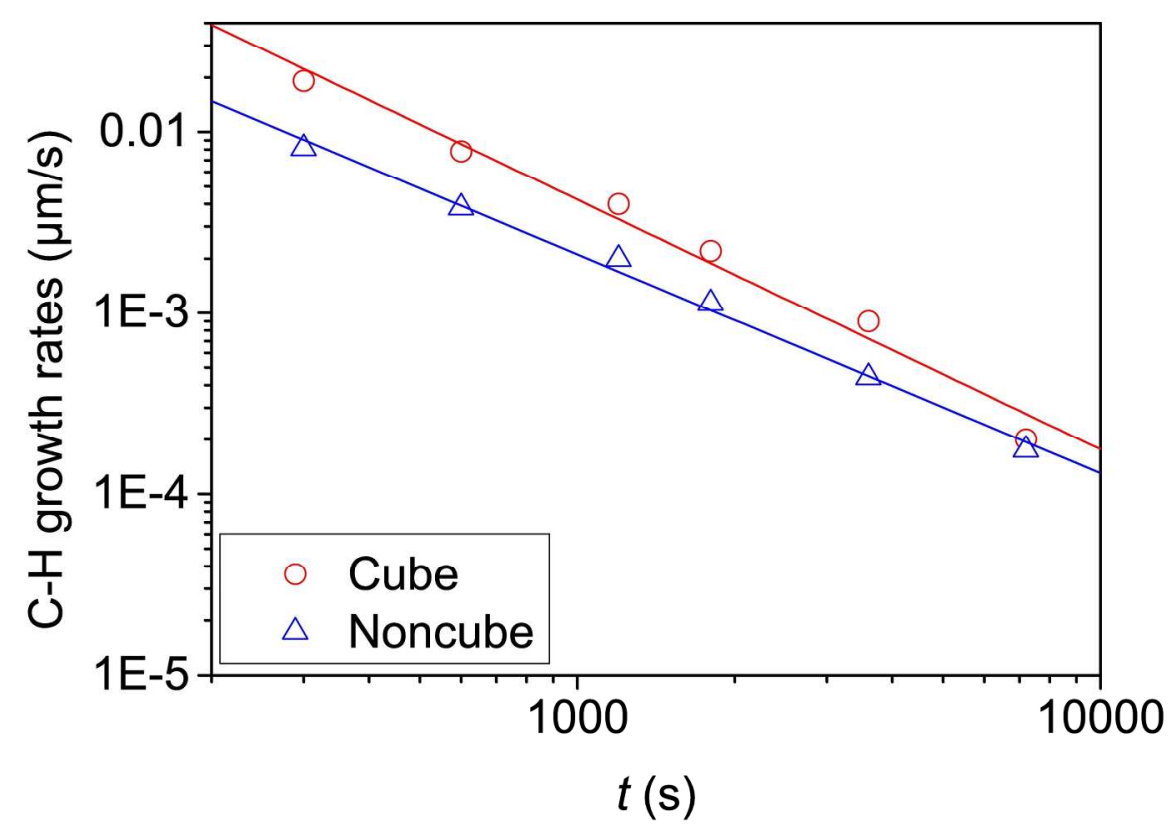

Figure 5 $201 \times 140 \mathrm{~mm}(300 \times 300$ DPI $)$ 


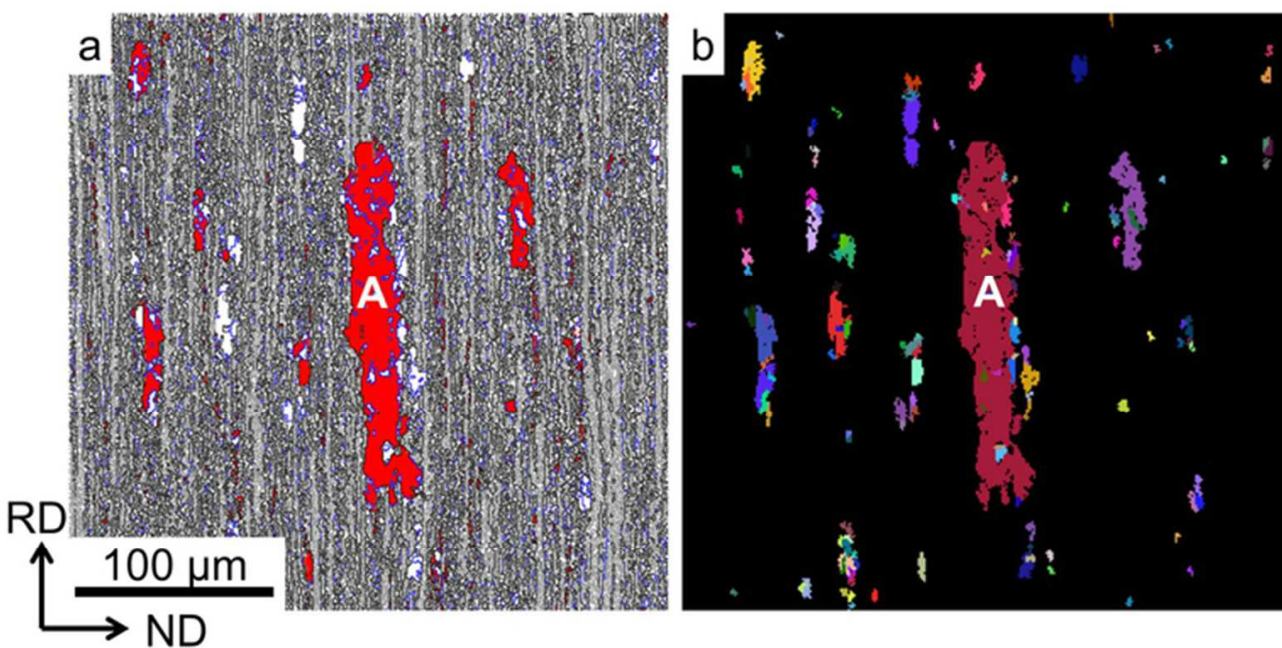

Figure 6

$65 \times 33 \mathrm{~mm}(300 \times 300 \mathrm{DPI})$ 

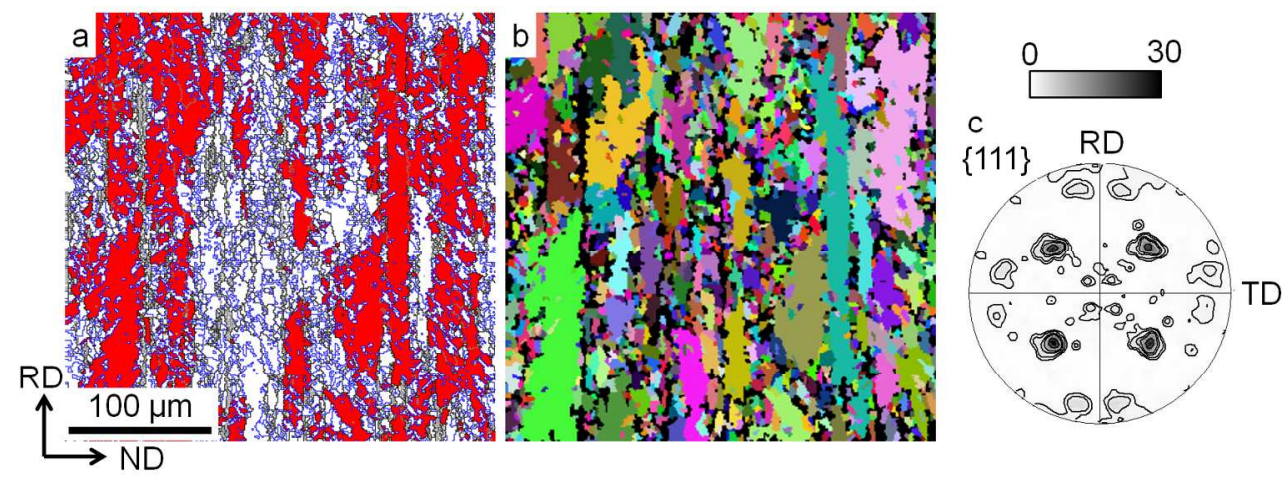

Figure 7

$701 \times 264 \mathrm{~mm}(72 \times 72$ DPI $)$ 


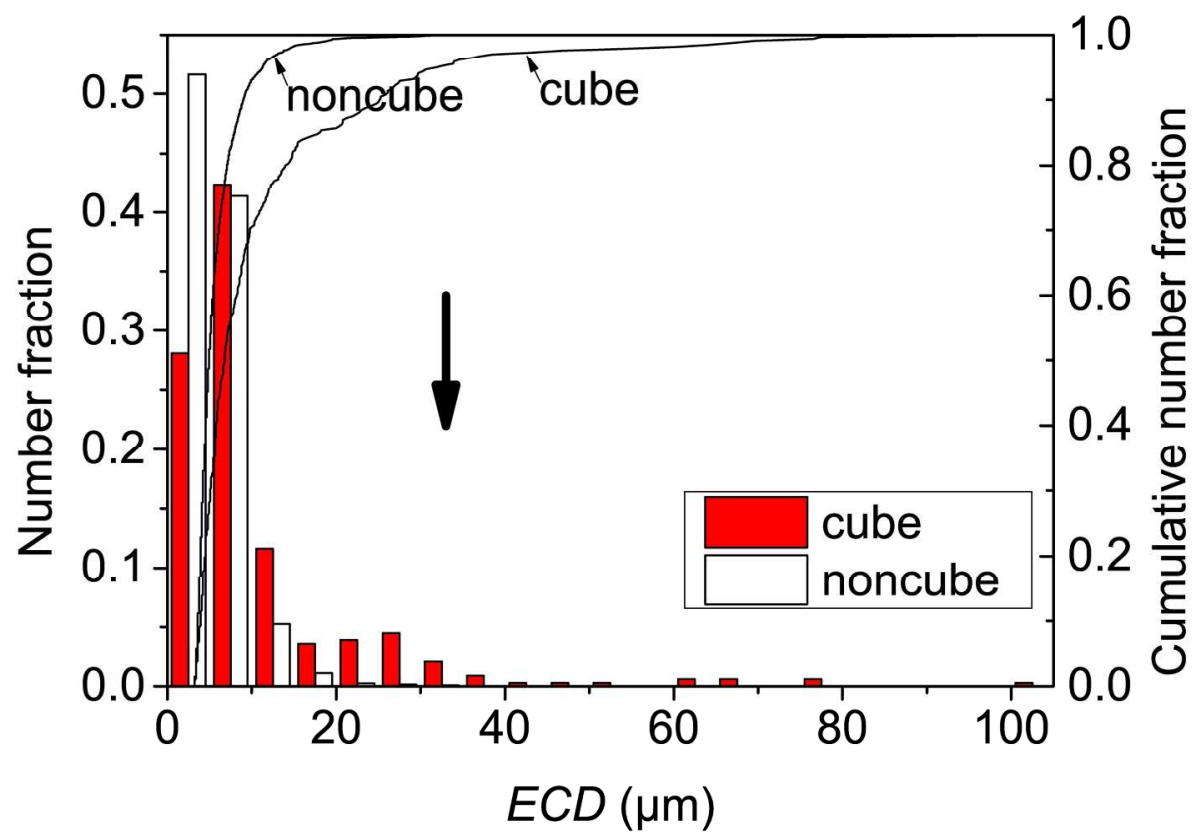

Figure $8 a$

$201 \times 140 \mathrm{~mm}(300 \times 300 \mathrm{DPI})$ 


1
2
3
4
5
6
7
8
9
10
11
12
13
14
15
16
17
18
19
20
21
22
23
24
25
26
27
28
29
30
31
32
33
34
35
36
37
38
39
40
41
42
43
44
45
46
47
48
49
50
51
52
53
54
55
56
57
58
60

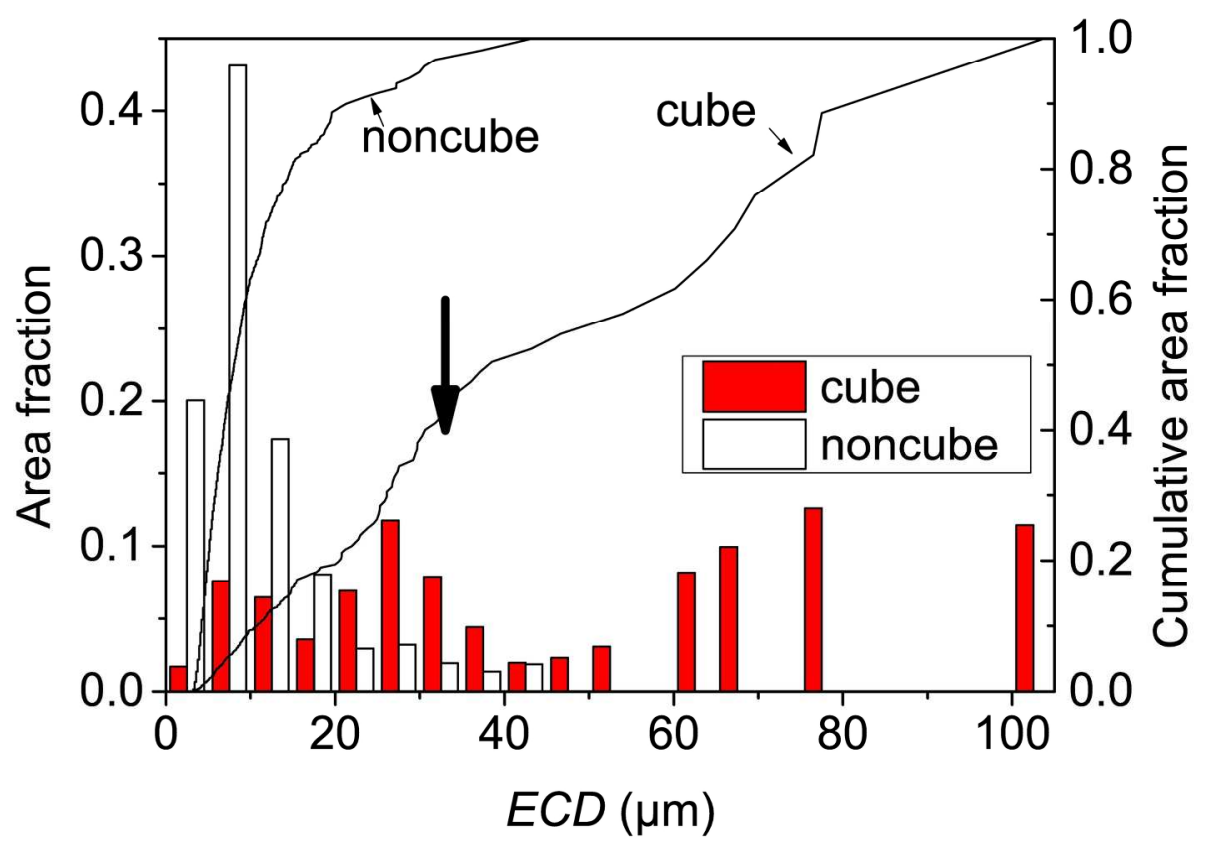

Figure $8 \mathrm{~b}$

$201 \times 140 \mathrm{~mm}(300 \times 300$ DPI) 
a

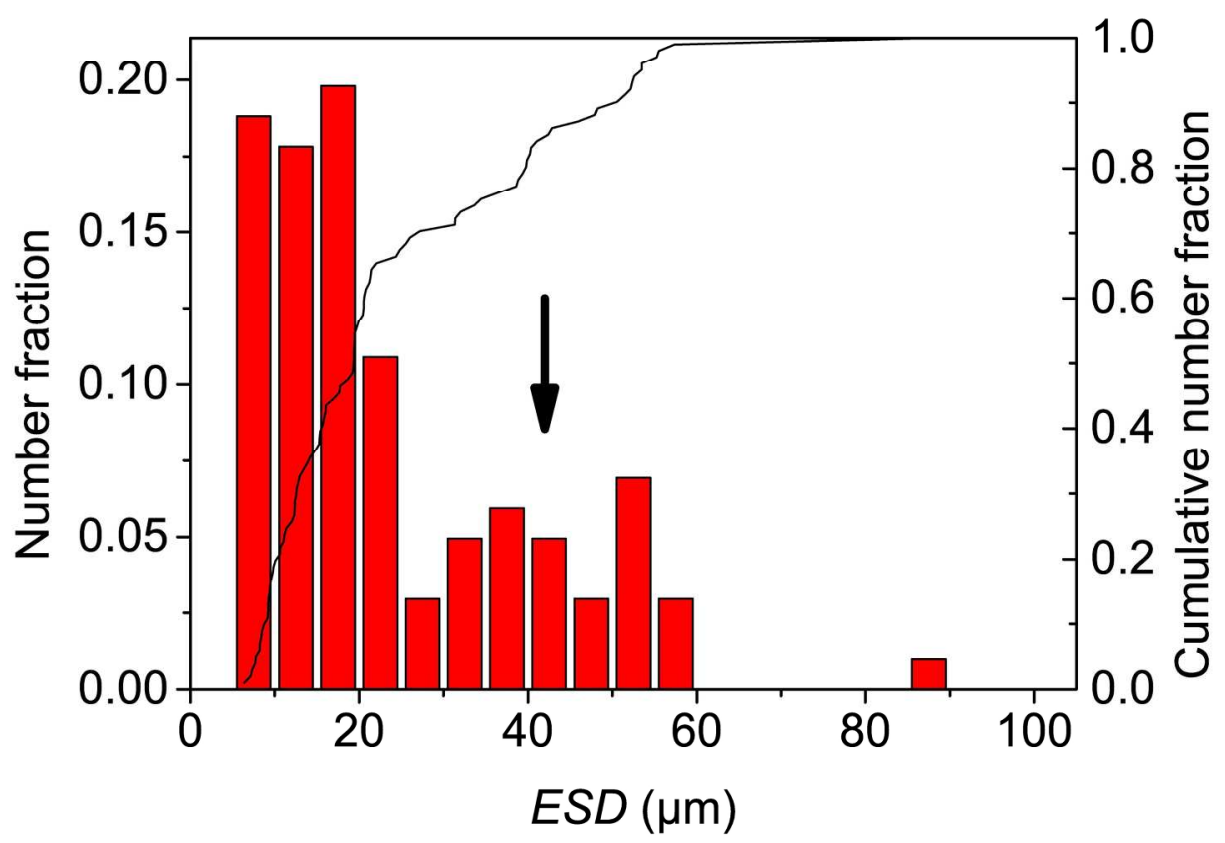

Figure 9a 201x140mm (300 x 300 DPI) 


1
2
3
4
5
6
7
8
9
10
11
12
13
14
15
16
17
18
19
20
21
22
23
24
25
26
27
28
29
30
31
32
33
34
35
36
37
38
39
40
41
42
43
44
45
46
47
48
49
50
51
52
53
54
55
56
57
58
60

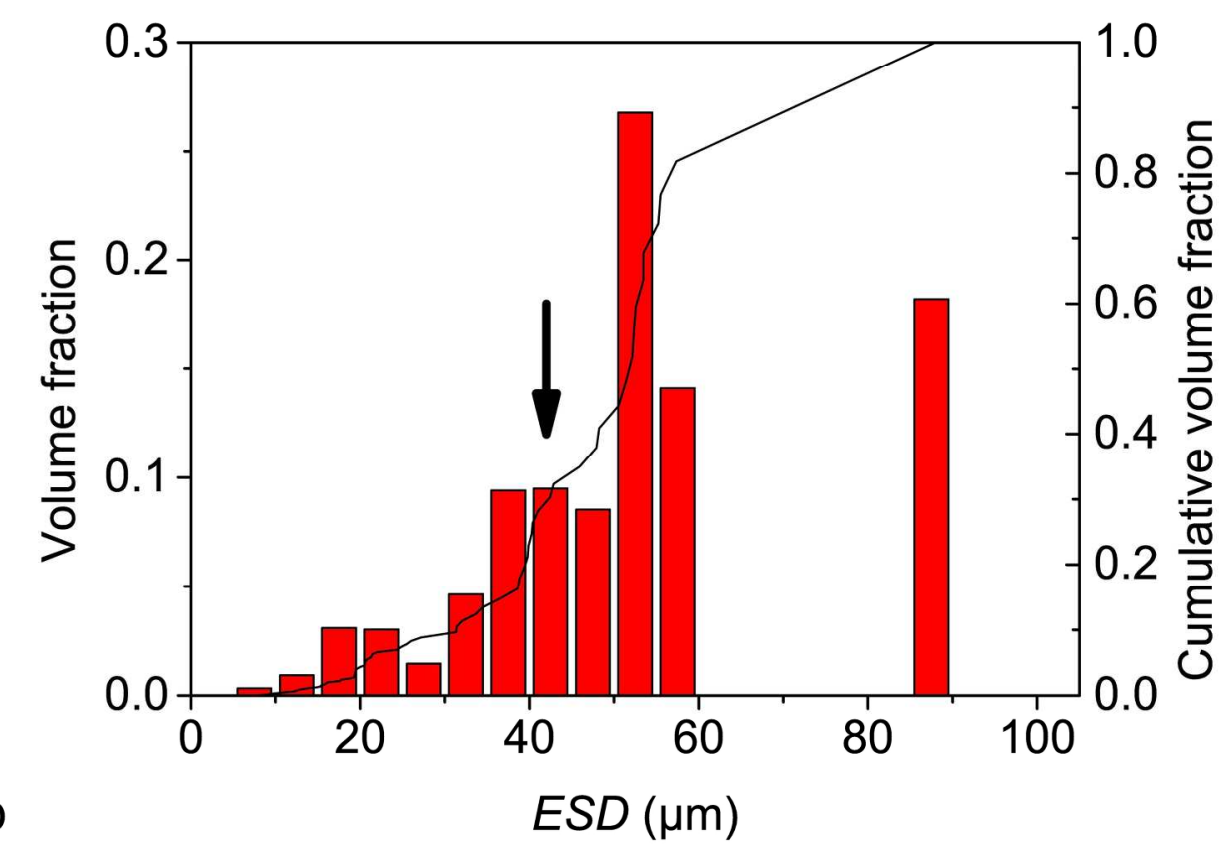

Figure9b

$201 \times 140 \mathrm{~mm}(300 \times 300$ DPI) 


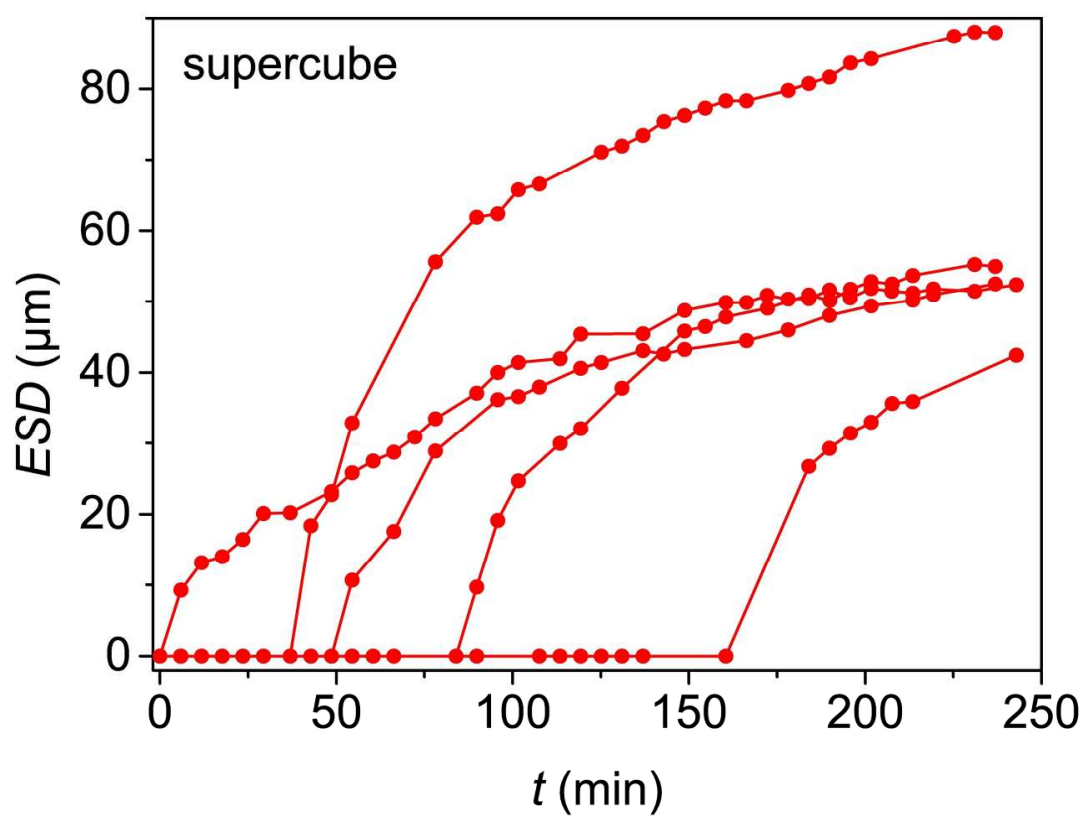

Figure 10a $201 \times 140 \mathrm{~mm}(300 \times 300$ DPI $)$ 
b

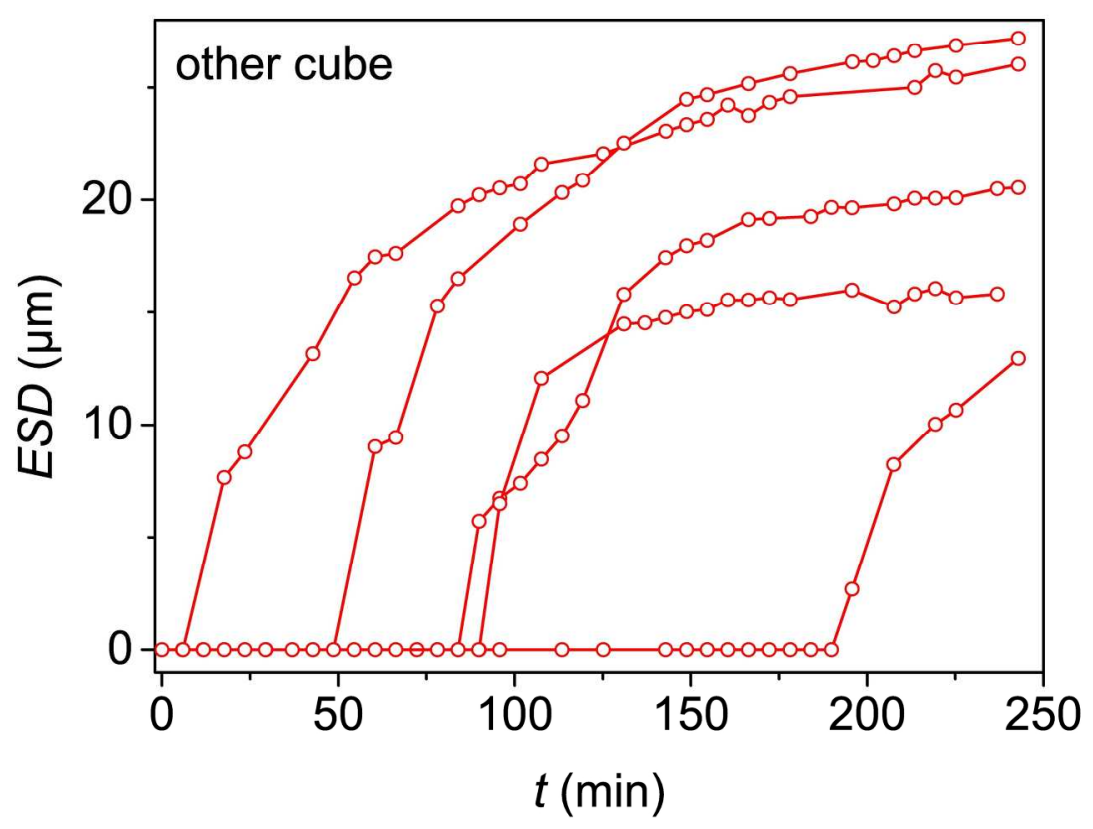

Figure $10 \mathrm{~b}$ $201 \times 140 \mathrm{~mm}(300 \times 300$ DPI $)$ 


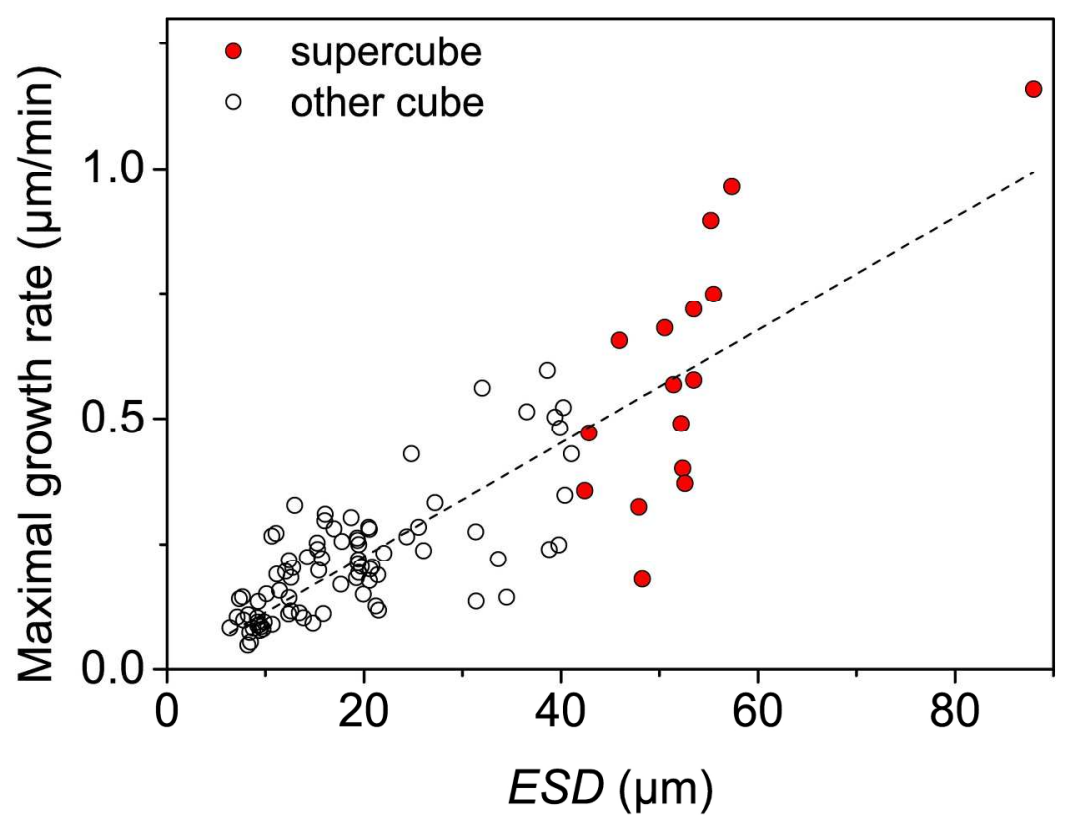

Figure 11

$201 \times 140 \mathrm{~mm}(300 \times 300$ DPI) 


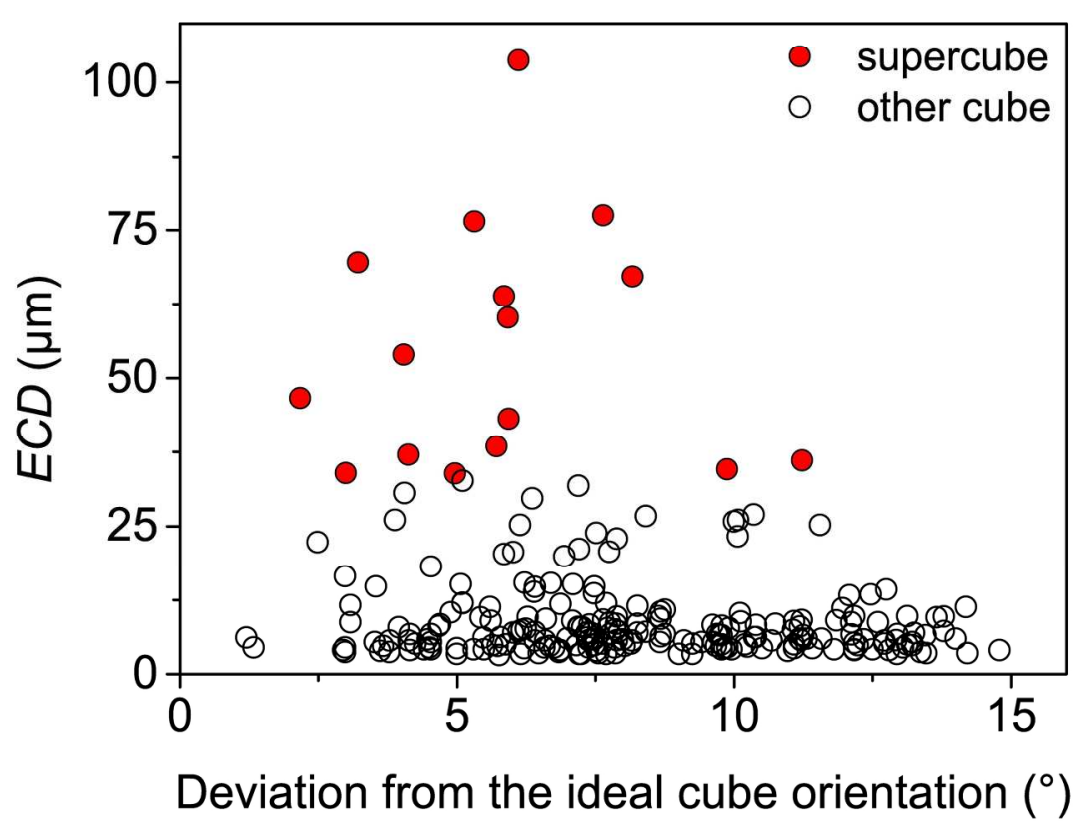

Figure 12

$201 \times 140 \mathrm{~mm}(300 \times 300$ DPI $)$ 

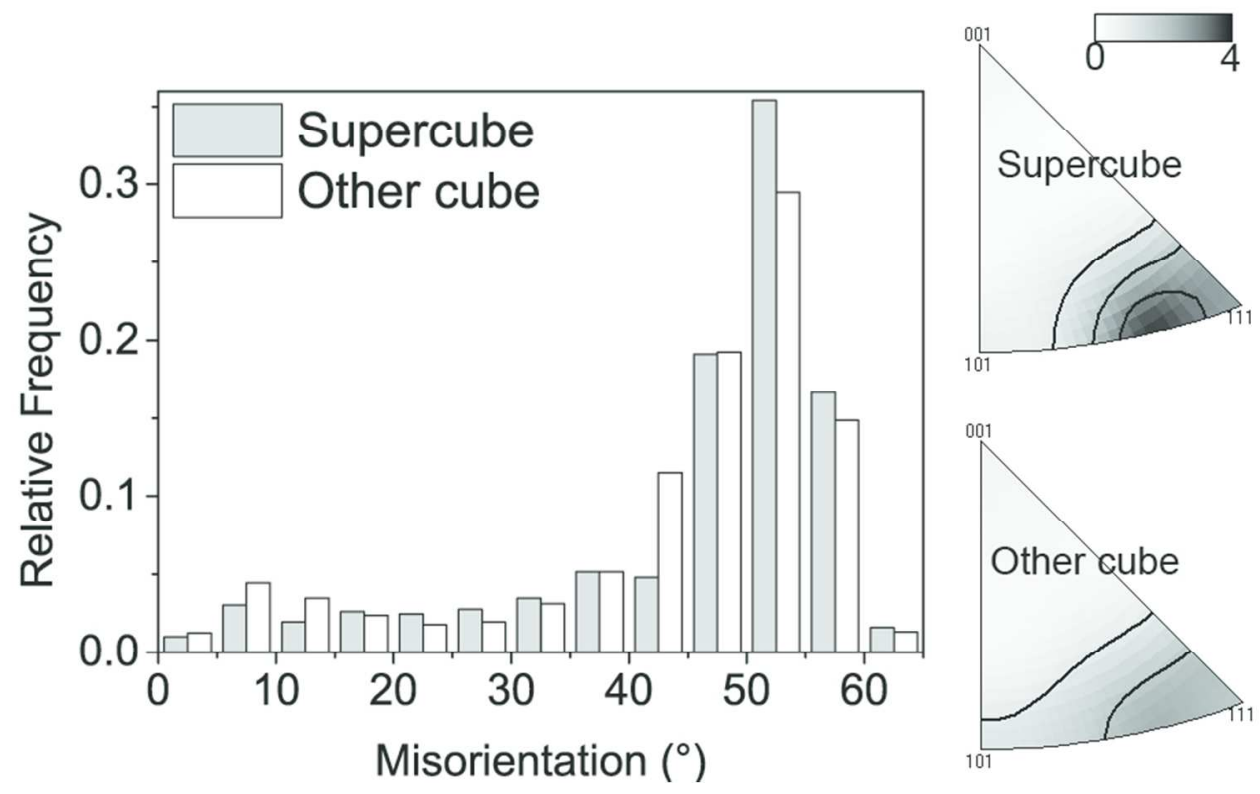

Figure 13 $335 \times 201 \mathrm{~mm}(72 \times 72$ DPI $)$ 

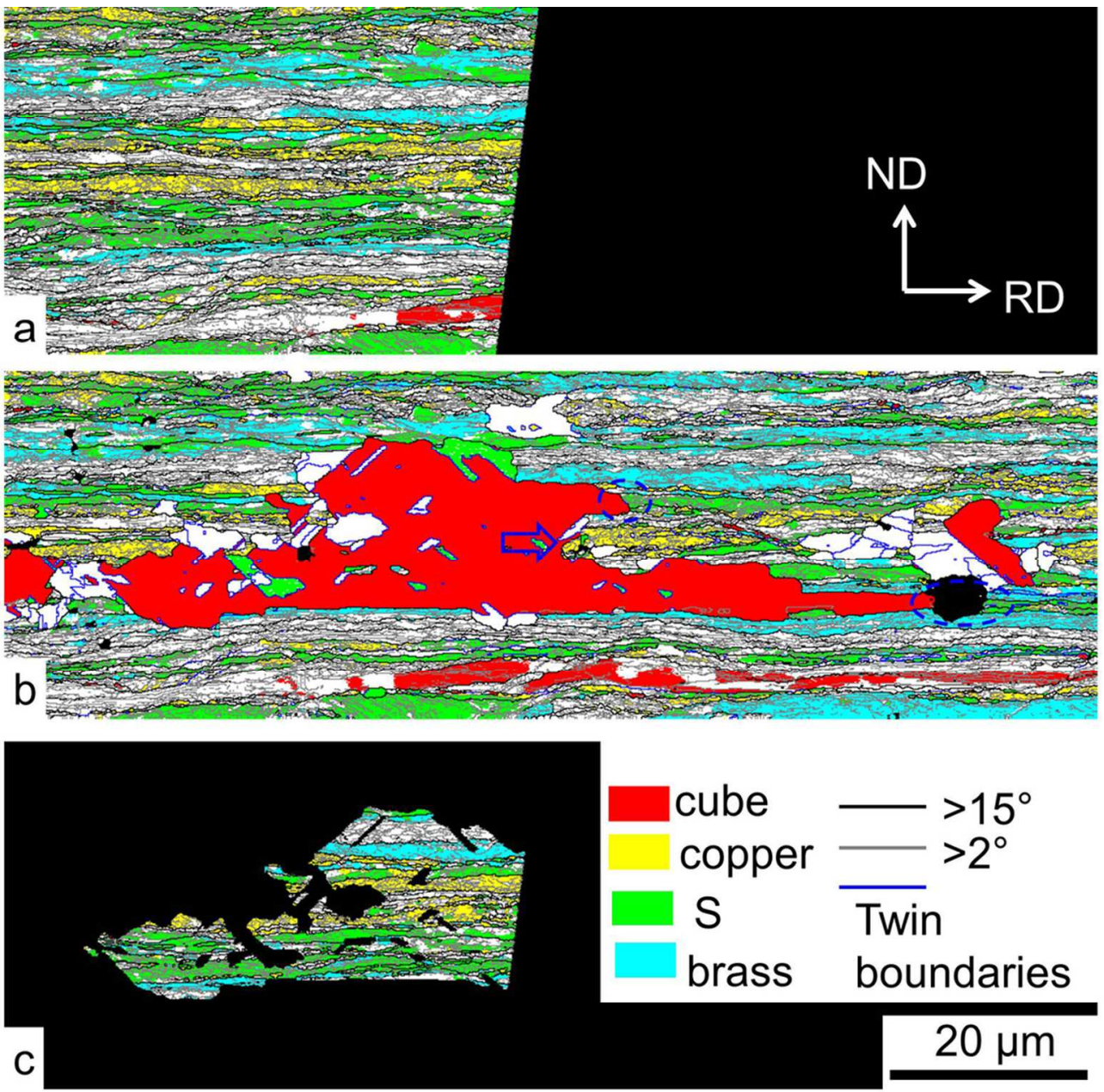

Figure 14

98x97mm (300 x 300 DPI $)$ 


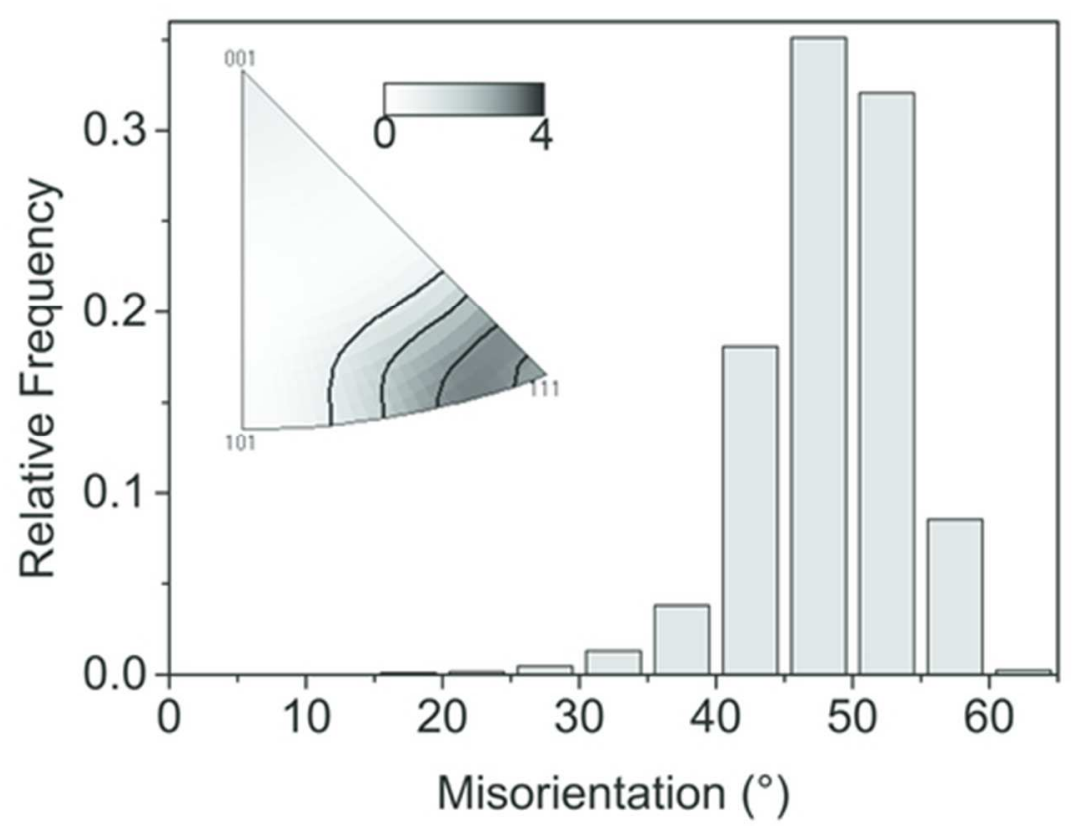

Figure 15

$48 \times 34 \mathrm{~mm}(300 \times 300 \mathrm{DPI})$ 


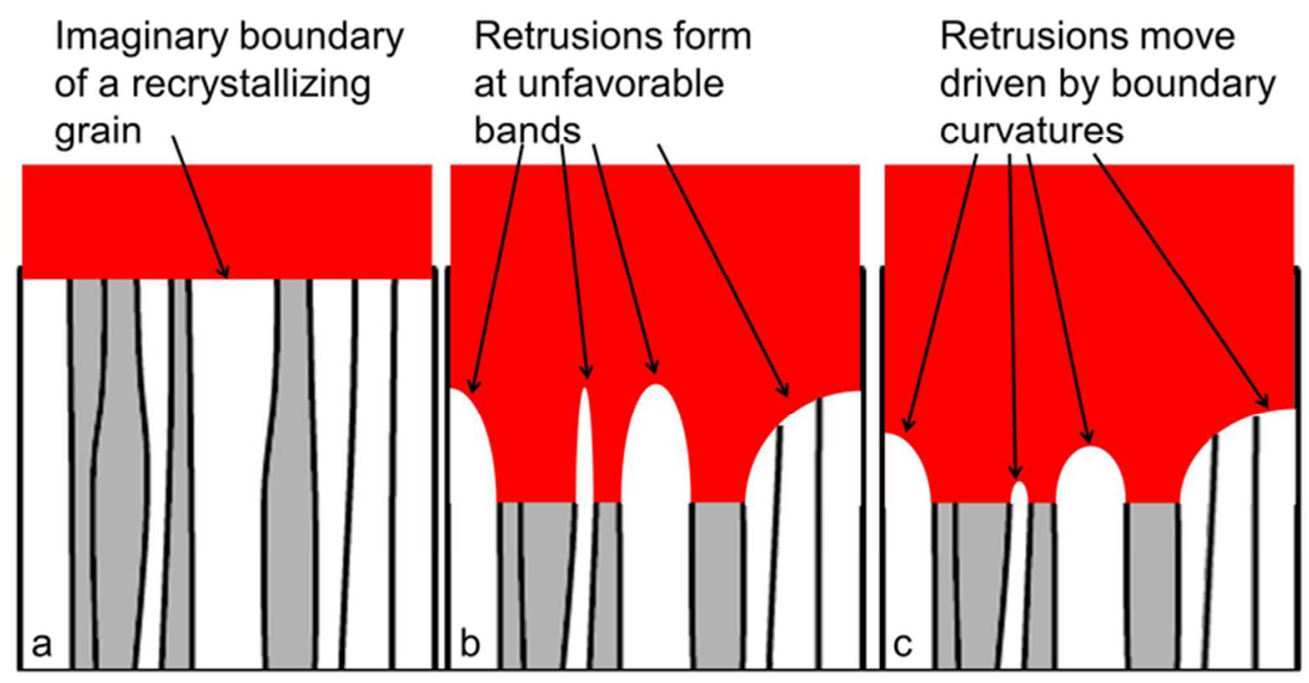

Figure 16

$66 \times 35 \mathrm{~mm}(300 \times 300$ DPI $)$ 